\title{
Article \\ Selective C-C Bond Cleavage in Diols and Lignin Models: High-Throughput Screening of Metal Oxide-Anchored Vanadium in Mesoporous Silica
}

\author{
Xinnan Lu ${ }^{1,2,3} \mathbb{D}^{\mathbb{D}}$, Roxanne Clément ${ }^{2} \mathbb{D}$, Yong Lu ${ }^{3}$, Belén Albela ${ }^{1} \mathbb{D}, \mathrm{R}$. Tom Baker ${ }^{2, *}$ and Laurent Bonneviot ${ }^{1, *}$ \\ 1 Laboratoire de Chimie, Ecole Normale Supérieure de Lyon, Université de Lyon, 46 Allée d'Italie, CEDEX 07, \\ 69364 Lyon, France; xinnan.lu@ku.ac.ae (X.L.); belen.albela@ens-lyon.fr (B.A.) \\ 2 Department of Chemistry and Biomolecular Sciences and Centre for Catalysis Research and Innovation, \\ University of Ottawa, Ottawa, ON K1N 6N5, Canada; r.clement@uottawa.ca \\ 3 School of Chemistry and Molecular Engineering, East China Normal University, No. 3663 North Zhongshan \\ Road, Shanghai 200062, China; ylu@chem.ecnu.edu.cn \\ * Correspondence: rbaker@uottawa.ca (R.T.B.); laurent.bonneviot@ens-lyon.fr (L.B.); \\ Tel.: +1-613-562-5800 (ext. 7108) (R.T.B.); +33-472-72-83-91 (L.B.)
}

check for updates

Citation: Lu, X.; Clément, R.; Lu, Y.; Albela, B.; Baker, R.T.; Bonneviot, L. Selective C-C Bond Cleavage in Diols and Lignin Models:

High-Throughput Screening of Metal Oxide-Anchored Vanadium in Mesoporous Silica. Catalysts 2021, 11, 901. https://doi.org/10.3390/ catal11080901

Academic Editor: Laurent Djakovitch

Received: 18 June 2021

Accepted: 20 July 2021

Published: 26 July 2021

Publisher's Note: MDPI stays neutral with regard to jurisdictional claims in published maps and institutional affiliations.

Copyright: (c) 2021 by the authors. Licensee MDPI, Basel, Switzerland. This article is an open access article distributed under the terms and conditions of the Creative Commons Attribution (CC BY) license (https:/ / creativecommons.org/licenses/by/ $4.0 /)$.
Abstract: The development of selective and robust heterogeneous oxidation catalysts is an enabling technology for conversion of biomass-derived platform chemicals. Vanadium active sites were incorporated into the structure of mesoporous silica via an ultra-fast, one-pot synthesis method based on microwave-assisted heating. In addition, $\mathrm{Al} / \mathrm{Ti} / \mathrm{Zr} / \mathrm{Ce}$ anchoring ions were introduced in order to minimize vanadium leaching and better control its dispersion. The supported $\mathrm{V}-(\mathrm{Al} / \mathrm{Ti} / \mathrm{Zr} / \mathrm{Ce})-$ MCM-41 composite materials were assessed as catalysts for aerobic $C-C$ bond cleavage of simple models for lignin (1,2-diphenyl-2-methoxyethanol) and sugar-derived polyalcohols (meso-hydrobenzoin). The $T i^{I V}$ ions proved to be the best anchors to prevent $\mathrm{V}$ leaching, while $A l^{I I I}$ and $Z r^{I V}$ ions were the best to improve selective conversion of the substrates. The active sites in these catalysts are shown to be $2 \mathrm{D} \mathrm{VO}_{\mathrm{x}}$ layers stabilized on the anchors. In a screen of twelve solvents, weakly polar solvents like toluene were found to be most suitable for this reaction, as was environmentally friendly ethyl acetate. The above properties, together with the high selectivity for $\mathrm{C}-\mathrm{C}$ bond cleavage, advocate for a heterogeneous catalytic pathway, intrinsically different from that reported previously for molecular oxovanadium (V) catalysts.

Keywords: mesoporous silica; heterogeneous catalysis; oxidative $\mathrm{C}-\mathrm{C}$ bond cleavage; vanadium; lignin model

\section{Introduction}

Recently, there has been increased interest in catalyst development for biomass conversion [1-3]. Principal components of biomass include cellulose and hemicellulose (sugar platform) as well as lignin, the most promising biomass source of aromatics. Much progress has been made in catalysis with applications to both the sugar and lignin platforms [4,5]. Lignin is a heterogeneous polymer made up of methoxylated phenoxy propanol units and has been depolymerized mainly by cleavage of $\mathrm{C}-\mathrm{O}$ bonds using both oxidative and reductive approaches [6,7]. Alternative cleavage of $\mathrm{C}-\mathrm{C}$ bonds, however, could afford different product slates from real lignin extracts [8].

Previous work with homogenous oxovanadium catalysts showed selective $\mathrm{C}-\mathrm{O}$ or $\mathrm{C}-\mathrm{C}$ bond cleavage, depending on ancillary ligands $[9,10]$. Mechanistic studies on lignin models in the presence of base demonstrated initial oxidation of benzylic alcohols to ketones followed by C-C bond cleavage [11-14]. In contrast, copper homogeneous catalysts showed direct $C-C$ bond cleavage of the alcohols [15]. In an effort to facilitate catalyst separation, Bolm and Corma combined $\mathrm{V}$ and $\mathrm{Cu}$ in a heterogeneous catalyst [16]. The observed catalytic activity, however, was shown to result from extensive catalyst leaching. 
Vanadium is typically supported on inorganic oxides such as $\mathrm{SiO}_{2}, \mathrm{TiO}_{2}, \mathrm{Al}_{2} \mathrm{O}_{3}$, or $\mathrm{ZrO}_{2}$ that are known to affect both catalytic activity and resistance to vanadium leaching [17]. Indeed, the dispersion of vanadium varies from monolayers to isolated species, depending on the support and the electronegativity of the oxide metal ion [18]. The use of hybrid supports such as $\mathrm{MO}_{X} / \mathrm{SiO}_{2}$ is also desirable with $\mathrm{M}=\mathrm{Al}, \mathrm{Nb}, \mathrm{Ta}, \mathrm{Ti}, \mathrm{Zr}$, and $\mathrm{Ce}[17,18]$. We have recently shown that nanorafts and oligomers of $\mathrm{TiO}_{2}$ can be stabilized on a mesostructured porous silica of MCM-41 type with improved resistance to leaching [19]. The advantage of this type of silica is the very large surface area and the possibility of using a molecular patterning technique to control the size of the supported $\mathrm{TiO}_{\mathrm{x}}$ nanoislets [19]. These nano-islets are indeed ideal to downsize anchored vanadium species and minimize leaching [20]. In both cases, the blue shift of the charge-transfer band was found to be decisive in characterizing this downsizing effect $[19,20]$. This shift was measured using a Tauc plot to extract the optical gap, known to be related to the reactivity [21-23].

Grafting metal oxide islets to the support before vanadium deposition affords better control of the surface modification and a better anchoring effect [19]. Nonetheless, favorable effects can still be observed when $T i^{I V}$ or $A l^{I I I}$ anchors are directly introduced into the synthesis of templated mesoporous silica [20]. In addition, the synthesis duration can be reduced from days to minutes using microwave-assisted autoclave treatments. This type of synthesis can be applied to many different silica and polymeric mesoporous systems such as MCM-41, SBA-15, FDU-1, and PSU-1 [24,25]. Recently, we showed that shorter times $(2-10 \mathrm{~min})$ and higher temperature $\left(\mathrm{T}=180^{\circ} \mathrm{C}\right)$ are optimal to reach a better mesostructuring for pure silica MCM-41 [26]. We still need to investigate whether directly introducing the anchoring ions using microwave-assisted syntheses produces an efficient anchoring effect and even further when the anchored vanadium ions are introduced together with the anchors.

We address this problem here by supporting $V^{V}$ ions using $A l^{I I I}, \mathrm{Ti}^{I V}, \mathrm{Zr}{ }^{I V}$, or $\mathrm{Ce} e^{I V}$ anchors. The catalysts were ranked by their anchoring effect and vanadium dispersion, using the blue-shift of the $V^{V}$ ion LMCT band measured by UV-visible spectroscopy and Tauc plot analysis. The large series of samples so obtained was then subjected to high throughput catalytic testing. The catalytic activity and selectivity with regard to $\mathrm{C}-\mathrm{C}$, $\mathrm{C}-\mathrm{H}$, and $\mathrm{C}-\mathrm{O}$ bond cleavage in aerobic oxidation were assessed using simple models for lignin (1,2-diphenyl-2-methoxyethanol; (1) and for sugar-derived polyalcohols (mesohydrobenzoin; (2) (Scheme 1). We also screened solvents in order to optimize reactivity, recycling, and resistance to leaching.

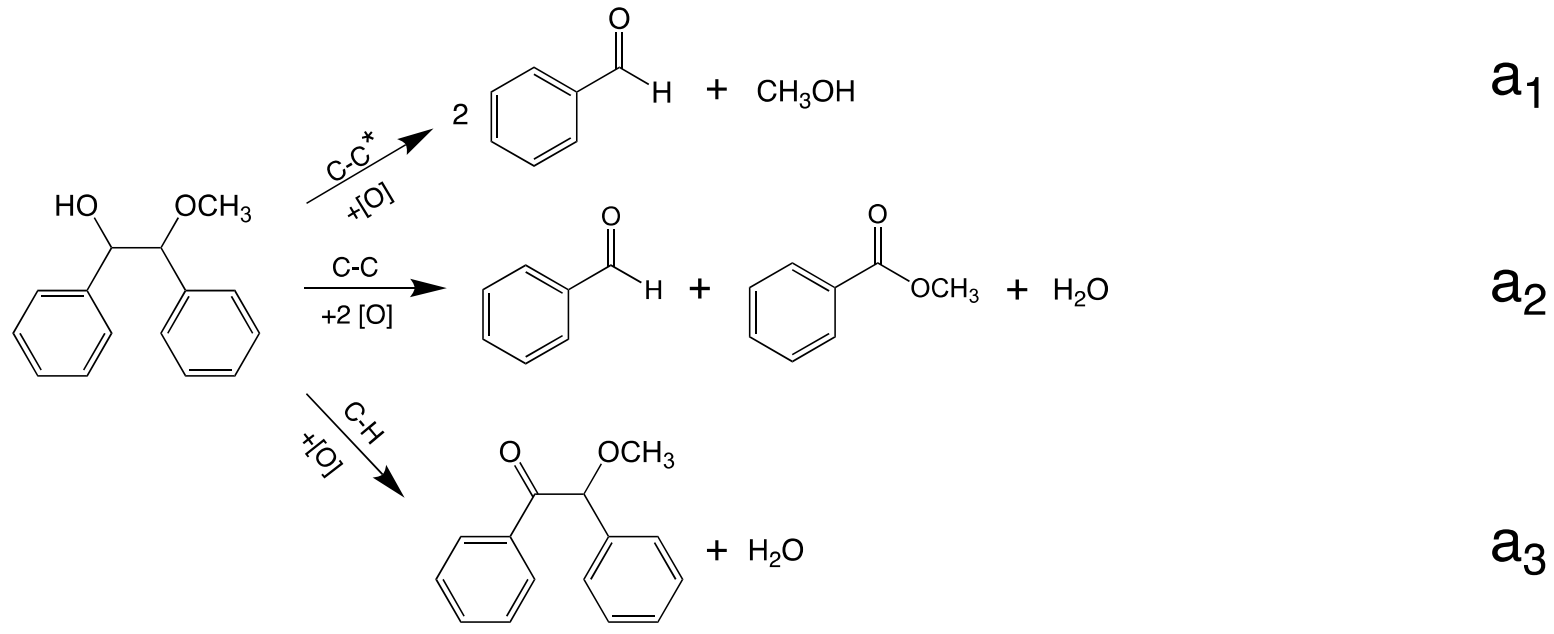

Scheme 1. Cont. 


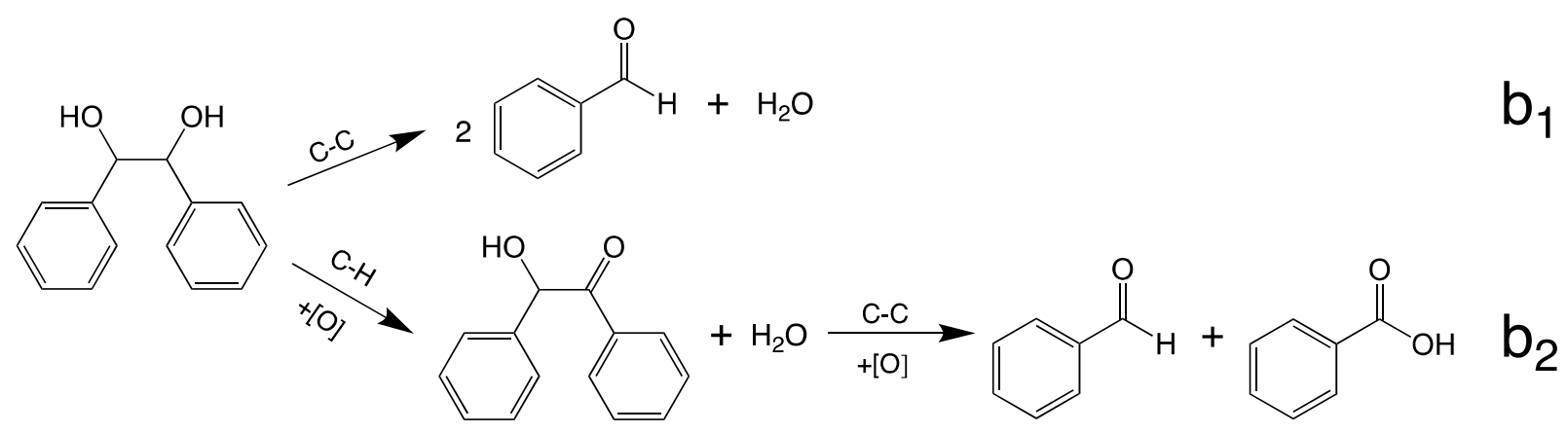

Scheme 1. Degradation pathways of 1,2-diphenyl-2-methoxyethanol $\left(\mathbf{a}_{1}-\mathbf{a}_{3}\right)$ and meso-hydrobenzoin $\left(\mathbf{b}_{1}, \mathbf{b}_{\mathbf{2}}\right)$ : route $\mathbf{a}_{\mathbf{1}}$ implies $\mathrm{C}-\mathrm{C}$ and $\mathrm{C}-\mathrm{O}$ bond cleavage noted $\mathrm{C}-\mathrm{C}^{*}$ with one oxygen atom transfer noted $+[\mathrm{O}]$; routes $\mathbf{a}_{\mathbf{2}}$ and $\mathbf{b}_{\mathbf{1}}$ involve direct $\mathrm{C}-\mathrm{C}$ bond cleavage and routes $\mathbf{a}_{3}$ and $\mathbf{b}_{2}$ involve $\mathrm{C}-\mathrm{H}$ bond cleavage. While the latter step is followed by $\mathrm{C}-\mathrm{C}$ bond cleavage in route $\mathbf{b}_{2}$, route $\mathbf{a}_{3}$ leads to benzoin methyl ether that does not react further under our reaction conditions.

\section{Results and Discussion}

\subsection{Synthesis}

A mesoporous silica of MCM-41 type was first prepared using microwave-assisted heating. The obtained solids are named MS-L or MS-T when the mesoporous silica was prepared from Ludox or tetraethoxysilane (TEOS) as silica precursors, respectively. In both cases, optimized conditions described previously for pure silica were adopted [27]. The cetyltrimethylammonium tosylate salt (CTATos) was preferred over the bromide salt, and mother solutions were adapted in each case as detailed in the Section 4 . The samples were then calcined at $550{ }^{\circ} \mathrm{C}$ under airflow for $6 \mathrm{~h}$ to remove the surfactant. Note that the metal precursors were chosen from those found in the literature, namely, tetrabutylorthotitanate (TBOT) for $\mathrm{Ti}^{4+}$, aluminum sulfate for $\mathrm{Al}^{3+}$, zirconium oxynitrate for $\mathrm{Zr}^{4+}$, and cerium acetylacetonate for $\mathrm{Ce}^{4+}$ (details in SI). In addition, the concentration of surfactant was increased to optimize the quality of the hexagonal ordering of the pores of the templated mesoporous silica. The fact that we used different precursors and types of metals introduced differences that are commented on below, the first one being the level of metal incorporation in the final product.

Chemical analyses revealed that the molar percentage is not necessarily equal to that of the mother liquor, revealing an incomplete incorporation of the elements depending on the precursors (Table 1). In the case of $\mathrm{Ti}$ and $\mathrm{Ce}$, the analyses match well with the value in the mother liquor when the silica precursor was TEOS. In these two cases, the yields are close to $100 \%$ for these elements. Concomitantly, the yield in vanadium was much lower, $\sim 30 \%$ in the presence of titanium and $\sim 50 \%$ in the presence of Ce, assuming that the yield in $\mathrm{Ti}, \mathrm{Ce}$, and silica precursors was close to $100 \%$. Conversely, when the precursor was Ludox, the percentage of $\mathrm{Al}$ and $\mathrm{Zr}$ was higher than in the mother liquor, as the yield in silica precursor was far from being total. It can be estimated at $~ 50$ and $\sim 60 \%$, assuming again a total incorporation of $\mathrm{Al}$ and $\mathrm{Zr}$ anchors, respectively. This is consistent with the yield reported for pure silica prepared from Ludox and microwave activation [27]. Thus, the differences in composition between the mother liquor and final solid are due to the specificity of each precursor, and this will be taken into account when anchoring and reactivity are discussed. The nominal values of the metal contents are those of the mother liquor. This was done to keep track of the catalysts' preparation and better understand their properties. 
Table 1. Metal loading and residual percentage after leaching test in methanol.

\begin{tabular}{|c|c|c|c|c|c|}
\hline No. & Catalyst & $\begin{array}{c}\mathrm{V}^{1} \\
\mathrm{~mol}^{2}\end{array}$ & $\begin{array}{c}\mathrm{M}^{1} \\
\mathrm{~mol} \%\end{array}$ & $\begin{array}{l}\mathrm{V}^{2} \\
\%\end{array}$ & $\begin{array}{r}\mathbf{M}^{2} \\
\%\end{array}$ \\
\hline 1 & (2.5-2.5)VTi-MS-T-cal & 0.69 & 2.8 & 83 & 100 \\
\hline 2 & (2.5-2.5)VAl-MS-L-cal & 2.2 & 4.8 & 49 & 93 \\
\hline 3 & (2.5-2.5) VZr-MS-L-cal & 2.2 & 4.1 & 50 & 100 \\
\hline 4 & (2.5-2.5) VCe-MS-T-cal & 1.2 & 2.5 & 60 & 61 \\
\hline 5 & (5-1)VTi-MS-T-cal & 2.21 & 1.12 & - & - \\
\hline 6 & (5-1)VAl-MS-L-cal & 3.90 & 2.11 & - & - \\
\hline 7 & $(1-0)$ V-MS-L-cal & 0.7 & - & 27 & - \\
\hline
\end{tabular}

\subsection{General Characteristics of $V$-(Ti/Al/Zr/Ce)-MS Catalysts}

The structure of the templated mesoporous silica was systematically checked from X-ray diffraction powder patterns available in Figures S1 and S2. All samples exhibit the typical 2D hexagonal pattern of good quality up to $5 \mathrm{M} / \mathrm{Si} \mathrm{mol} \%(\mathrm{M}=\mathrm{V}, \mathrm{Ti}, \mathrm{Ce}, \mathrm{Zr}, \mathrm{Al})$. In particular, three peaks assigned to $\langle 100\rangle,\langle 110\rangle$, and $\langle 200\rangle$ reflections of the $P 6 \mathrm{~mm}$ point group can be seen for these structures (Figure S1). This is consistent with the TEM pictures, showing the hexagonal array of pores for some grains well-oriented along the $\mathrm{z}$ axis or the set of channels along the transverse directions (Figure S3). When the anchor ion was $\mathrm{Ti}^{I V}$ or $C e^{I V}$, more metal—vanadium plus anchor-was introduced, up to $7.5 \mathrm{M} / \mathrm{Si} \mathrm{mol} \%$, leading to line broadening. This is consistent with a decreased size of ordered domains. Above this loading, the drastic loss of peak intensity evidences a collapse of the structure. No peaks were observed between $2 \theta$ of $7^{\circ}$ to $70^{\circ}$, indicating the absence of any crystalline metal oxides. This indicates that both metal ions participate in the siliceous wall formation, disrupting the regularity of the hexagonal mesostructure (Figure S2a). Adding $\mathrm{Al}^{\mathrm{III}}$ alone affects the structure much more than Ti or Ce alone. In this case, addition of vanadium together with $\mathrm{Al}$ improves the quality of the structure up to a total metal ion loading of $\sim 3 \mathrm{M} / \mathrm{Si} \mathrm{mol} \%$. Above this loading, the trend moves back to a loss of ordering when adding more metal ions (Figure S2b). The $\mathrm{Zr}^{I V}$ anchor, like $\mathrm{Al}^{I I I}$, induces a similar non-monotonic effect though affecting the structure less than $\mathrm{Al}^{\mathrm{III}}$ ions. These differences are the result of two conflicting stabilization processes: some heteroatoms may insert better into the siliceous wall than other heteroatoms like $\mathrm{Al}$, while the presence of a second heteroatom may either worsen the order by inserting as well in the pore wall or improve the order by segregating out with the other heteroatom as for $\mathrm{V}$ and $\mathrm{Al}$ (see ${ }^{27} \mathrm{Al}$ solid state NMR data for Al anchor, Table S3).

The $\mathrm{N}_{2}$ sorption isotherms of all the calcined samples exhibit the typical type IV isotherm according to the IUPAC classification (Figure S4 and Tables S1 and S2) [27,28]. The decrease of surface area, pore volume, and pore diameter varies in parallel with the structural information given, fingerprinting the insertion of the anchors and vanadium (Figure S4 and Table S2). Below $3 \mathrm{M} / \mathrm{Si} \mathrm{mol} \%$, the surface remains rather close to the heteroatom-free templated silica $\left(1000 \pm 40 \mathrm{~m}^{2} / \mathrm{g}\right)$. Further loss of surface and internal pore volume $(<15 \%)$ is observed in the intermediate loadings between 5 and $7.5 \mathrm{M} / \mathrm{Si}$ mol\%. Above these metal loadings the losses approach $25 \%$ of both surface area and pore volume. The pore diameter follows a different trend, depending more on the nature of the anchor than on its loading. Pore contraction $(\sim 10 \%)$ is observed in the presence of both $\mathrm{Ti}$ and $\mathrm{Ce}$ anchors while no effect is observed for $\mathrm{Al}$ and $\mathrm{Zr}$ anchors. In these two groups, $\mathrm{Zr}^{I V}$ and $\mathrm{Ce}^{I V}$ anchors are the metal ions that affect most the porous structure. Presumably, the larger size of the latter ions affects more the structural porosity with the localization on the silica-surfactant interface for $\mathrm{Ti}^{I V}$ and $\mathrm{Ce}^{I V}$ ions affecting more the pore diameter. At low loadings, the trend inversion for $\mathrm{V}-\mathrm{Al}$ and $\mathrm{V}-\mathrm{Zr}$ couples mirrors the improvement of crystallinity observed from the XRD patterns (Figure S2).

In the absence of vanadium, the ${ }^{27} \mathrm{Al}$ NMR spectrum showed a single resonance at $\sim 55 \mathrm{ppm}$ (tetrahedral species), and a very small signal at $\sim 5 \mathrm{ppm}$ (octahedral species), 
accounting for 0.8 and $2.3 \%$ for samples with 5 and $10 \mathrm{~mol} \% \mathrm{Al}$ (Al-MS-L, Table S3). No pentacoordinated Al sites ( $\sim 35 \mathrm{ppm})$ were detected. In the presence of vanadium (VAl-MS-L), the intensity of the octahedral species decreased to 0.5 and $0.6 \%$ for (1-5)VAl-MS-L and (1-10)VAl-MS-L, respectively. These results suggest that the few octahedral aluminum species are likely hydrated on the surface and react with vanadium to form a tetrahedral $\mathrm{Al}^{3+} \leftarrow \mathrm{O}=\mathrm{V}^{5+}$ Lewis adduct. The change of coordination of the $\mathrm{Al}$ sites implies the removal of adsorbed water upon formation of the vanadium layer, and the development of covalent V-O-Si bridges along with formation of surface vanadium Lewis adducts. Accordingly, $\mathrm{Al}$ remains mostly tetrahedral up to $10 \mathrm{Al} / \mathrm{Si}$ mol\% even in the presence of vanadium, while ${ }^{29} \mathrm{Si}$ solid state NMR shows the formation of more single $\left(\mathrm{Q}_{3}\right)$ and geminal $\left(\mathrm{Q}_{2}\right)$ silanol groups (Table $\mathrm{S} 4$ ). This is evidence that $\mathrm{Al}^{\mathrm{III}}$ ions alone incorporate preferentially to the core of the siliceous wall whereas they locate more at the interface when vanadium is present. The preferential location of $\mathrm{Ti}^{I V}$ at the silica-surfactant interface (and to a lesser extent for $\mathrm{Ce}^{I V}$ ) also explains the absence of a detectable synergetic effect with vanadium ions. All these structural observations advocate for the incorporation of both metals inside the structure and the trend for vanadium to be retained at the interface of the anchoring ions (like $\mathrm{Al}$ or $\mathrm{Zr}$ ) embedded in the pore wall.

Electron paramagnetic resonance (EPR) spectroscopy was used as a convenient technique to check for the presence of vanadium (IV) oxide species, which are paramagnetic $d^{1}$ species in the $\mathrm{VOSO}_{4}$ precursor [29,30]. EPR spectra of the as-prepared vanadium samples with $\mathrm{Ti} / \mathrm{Al} / \mathrm{Zr} / \mathrm{Ce}$ anchors exhibited a typical multiline signal corresponding to isolated vanadyl ions $\left(\mathrm{V}^{I V}=\mathrm{O}\right)^{2+}$ (Figure S6). After calcination in air, no EPR signal was observed, indicating that all the vanadium species were oxidized to $\left(\mathrm{V}^{V}=\mathrm{O}\right)^{3+}$. FTIR spectra confirmed the disappearance of the surfactant after calcination and a broadening in the range of 1000 to $1200 \mathrm{~cm}^{-1}$, where the $\mathrm{V}=\mathrm{O}$ vanadyl band is expected (Figure S7) [30].

\subsection{Effect of Anchoring on the Vanadium LMCT Band Blue-Shift}

The UV-visible spectra of vanadium samples (Figure 1) exhibit a large band between $200-500 \mathrm{~nm}$ that is attributed to a ligand to metal charge-transfer (LMCT). It clearly appears that the band is blue-shifted regardless of the nature of the anchors. The effect is strongest in the presence of the Ti anchors and weakest in the presence of the Ce anchors. Figure 2 depicts the typical trend on varying the loading of either vanadium or the Ti anchor. The effect is stronger at low vanadium loadings at least below $5 \mathrm{~V} / \mathrm{Si} \mathrm{mol}$ and weaker at low anchor loadings. A similar trend is also observed for $\mathrm{Al}, \mathrm{Zr}$ anchors (Figure S8). Note that the maximum shift is not obtained for the highest loading investigated for Ti or $\mathrm{Al}$ anchors $(10 \mathrm{~V} / \mathrm{Si} \mathrm{mol} \%)$, likely because of the partial loss of the hexagonal structure and the embedding of some of the Ti anchors in the collapsed region of the silica matrix. Note that in the presence of the $\mathrm{Zr}$ anchors the signal is weak, attesting to a low rate of $\mathrm{V}$ incorporation during the direct synthesis. In addition, the strong peak at $\sim 225 \mathrm{~nm}$ belongs to the $\mathrm{Zr}$ anchoring ions (Figure 1 and Figure $\mathrm{S} 8 \mathrm{~b}$ ). The case of Ce anchors is more problematic as its LMCT band is centered at $\sim 305 \mathrm{~nm}$ and masks most of the LMCT band of vanadium (Figure S8b). Despite this interference, the breadth of the total LMCT band reveals the presence of vanadium at high loading on the high wavelength side. The broadening disappears at low $\mathrm{V}$ or high Ce loadings, suggesting that $\mathrm{Ce}$ anchors produce a similar effect on vanadium (Figure $\mathrm{S} 8 \mathrm{~b}$ ). As a blue-shift characterizes a better dispersion of vanadium [31,32], a ranking of the anchors on the efficiency to improve vanadium dispersion can be proposed as follows: $\mathrm{Ti}>\mathrm{Ce}>\mathrm{Zr}>\mathrm{Al}>$ no anchors. In order to better compare the catalysts in this study and with other work it is convenient to quantify the LMCT band shift. 


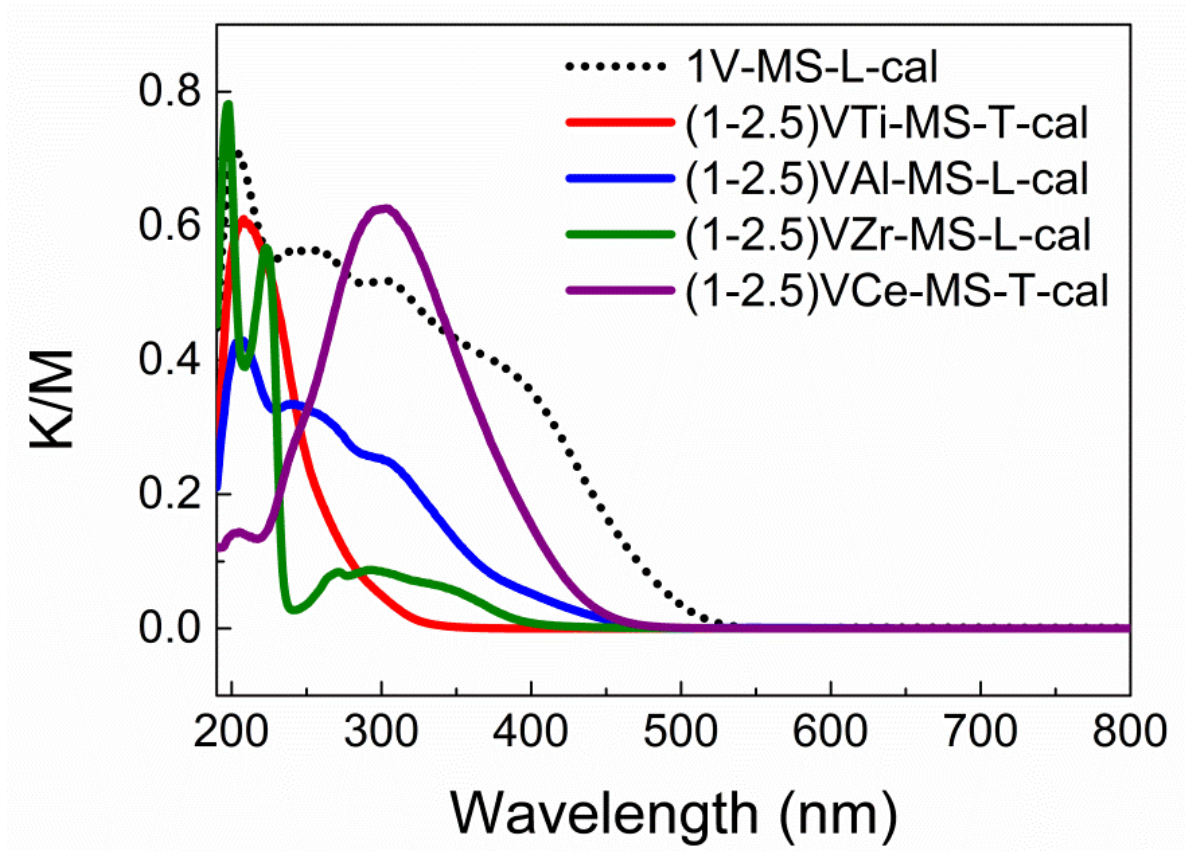

Figure 1. UV-vis spectra of 1V-MS-L-cal and (1-2.5)VY-MS-T/L-cal ( $\mathrm{Y}=\mathrm{Ti} / \mathrm{Al} / \mathrm{Zr} / \mathrm{Ce})$. MS-L-cal was used as blank, and before measurement, samples were diluted in MS-L-cal to keep the spectral intensity in the range of $0.2-0.8 \mathrm{~K} / \mathrm{M}(\mathrm{K} / \mathrm{M}=$ Kubelka-Munk function).
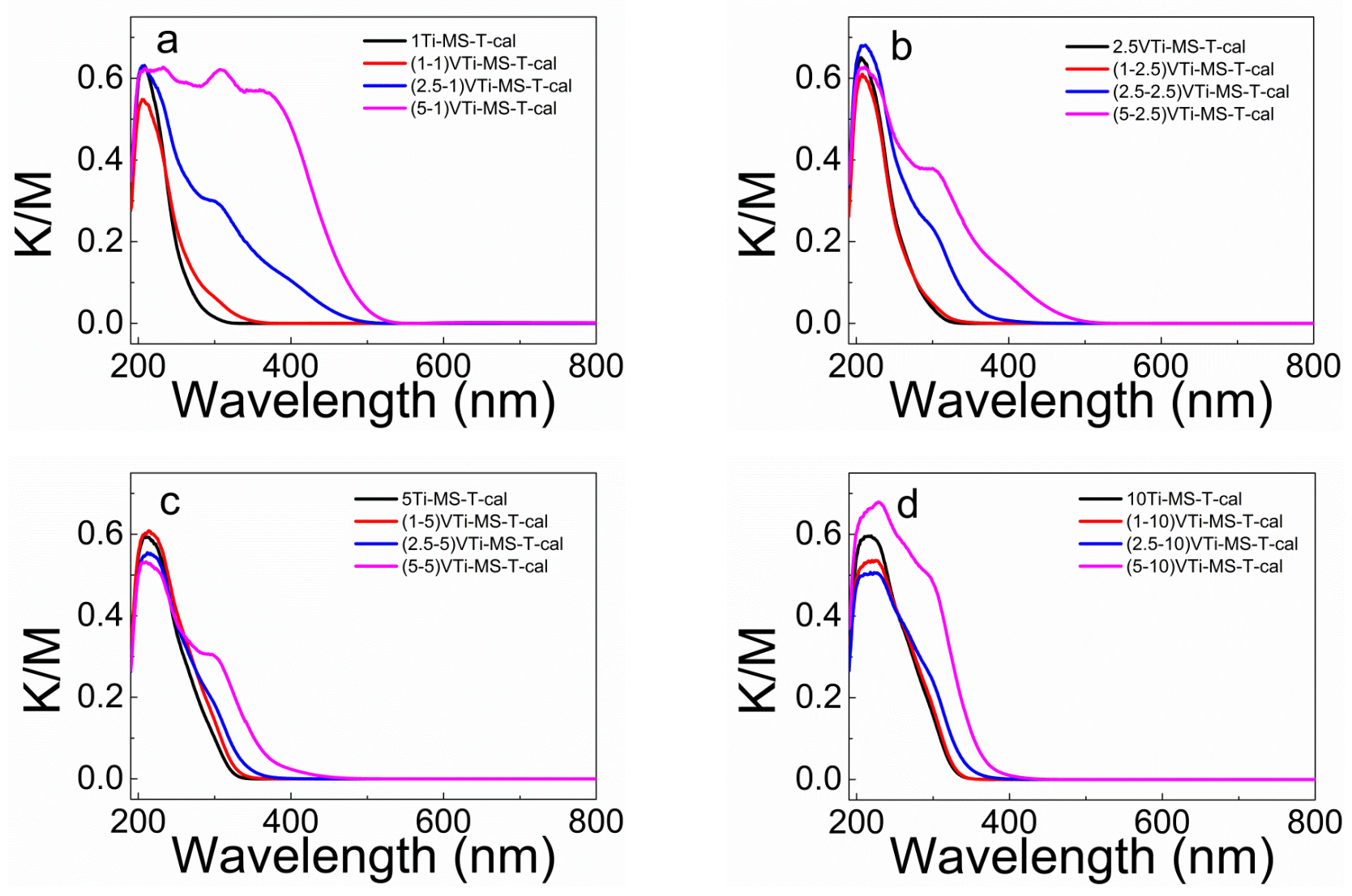

Figure 2. UV-vis spectra of VTi-MS-T-cal samples containing 1 (a), 2.5 (b), 5 (c) and 10\% (d) Ti anchors; MS-L-cal was used as blank, and before measurement, samples were diluted in MS-L-cal to keep the spectra intensity in the range of 0.2 to 0.8 K/M. K/M: Kubelka-Munk function (SI). 


\subsection{Measuring the Optical Gap to Quantify the LMCT Band Blue-Shift}

The position of the edge of the LMCT band corresponds to the so-called optical gap for colored materials and to the energy of the band gap, $E_{g}$, for semiconductors, both measured using a Tauc plot [21,22]. Weber showed that $E_{g}$ is correlated to the catalytic activity of molybdenum in heteropolyanions and heterogeneous catalysts [23]. Gao and Wachs further demonstrated that this correlation was true for supported vanadium heterogeneous catalysts, allowing them to rank $\mathrm{SiO}_{2}, \mathrm{Al}_{2} \mathrm{O}_{3}, \mathrm{TiO}_{2}, \mathrm{ZrO}_{2}$, and $\mathrm{CeO}_{2}$ oxide supports for their capacity to disperse the $\mathrm{V}$ ions [33]. It has been also applied on multilayered $\mathrm{M}_{(1)} \mathrm{O}_{\mathrm{x}} / \mathrm{M}_{(2)} \mathrm{O}_{\mathrm{x} 2} / \mathrm{SiO}_{2}$ hybrid catalysts prepared by impregnation on a nonporous silica $[18,34,35]$. We recently applied this technique to analyze the dispersion of $\mathrm{VO}_{\mathrm{x}} / \mathrm{AlO}_{\mathrm{x}} / \mathrm{MCM}-41$ and $\mathrm{VO}_{\mathrm{x}} / \mathrm{TiO}_{\mathrm{x}} / \mathrm{MCM}-41$ prepared according to a one-pot synthesis using a conventional thermal autoclaving aging [20]. It is applied presently to one pot synthesis using fast microwave-activated autoclaving with the same care required for measuring reflectance spectra (Figure S8).

The set of Tauc plots used to calculate optical gaps in the series of VAl-MS-L-cal samples are represented in Figure 3. For the other anchors, the plots are available in Figure S9. Note that the foot of the edge is well defined and allows us to measure $\mathrm{E}_{\mathrm{g}}$ with an accuracy of $\pm 0.1 \mathrm{eV}$. It was necessary to subtract the spectrum of the corresponding vanadium-free samples to minimize the interference with the LMCT band of the anchor ions. Overestimation of the blue-shift of 0.2 to $0.5 \mathrm{eV}$ was avoided particularly in (1-1), (1-2.5), (1-5), and (1-10) VTi-MS-T-cal samples showing the largest effects (Figure S9a). The optical gap can be compared advantageously to reference compounds like orthovanadate, $\mathrm{NH}_{4} \mathrm{VO}_{4}$, divanadate, $\mathrm{Mg}_{2} \mathrm{~V}_{2} \mathrm{O}_{7}$, linear metavanadate, orthovanadates, one finds (5-5) VTi-MS-T-cal, (1-2.5) VAl-MS-L-cal, and (1-5) VZr-MS-L-cal. The rest of our samples fall in the red-shifted region $(2.4-2.8 \mathrm{eV})$ that is not bulk vanadium but rather assigned to $2 \mathrm{D}$ rafts $[33,36,37]$. A better overview of the anchor effect on the dispersion can be found in Figure 3 where the trend is compared for 2.5 Anchor/Si mol\% and different loadings of vanadium. A better-defined ranking depending on vanadium loading can be now proposed from the higher to the lower dispersion: $\mathrm{Ti}>\mathrm{Al}>\mathrm{Ce} \approx \mathrm{Zr}>$ no anchor at low $\mathrm{V}$ loadings and $\mathrm{Ti}>\mathrm{Ce} \approx \mathrm{Zr}>\mathrm{Al}>$ no anchors at high $\mathrm{V}$ loadings. The presence of $\mathrm{V}_{2} \mathrm{O}_{5}$ can be discounted and the above analysis will allow for correlation between vanadium dispersion and catalytic reactivity/selectivity to be made. As we shall see below, the structural correlation does not require a deeper analysis based for instance on a Gaussian fitting of the full LMCT band [38,39].
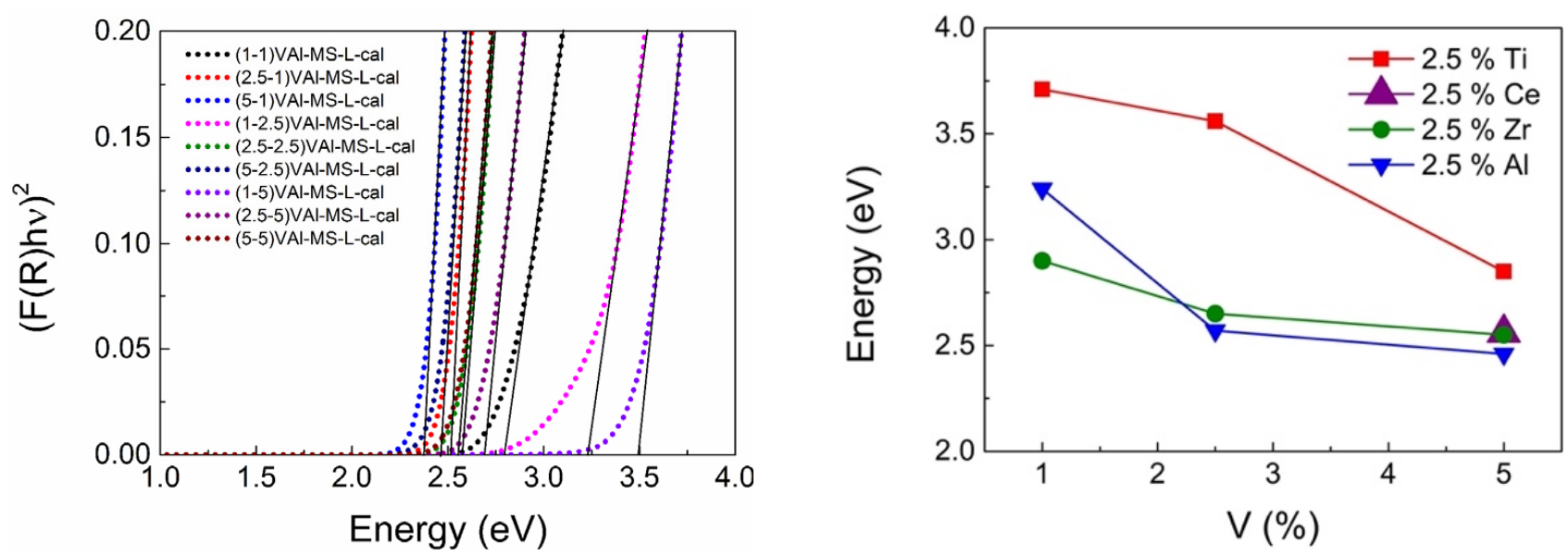

Figure 3. Tauc plots and determination of the optical gap, $E_{g}$, by linear extrapolation (left) and, evolution of $E_{g}$ depending on the loading and nature of the anchors (right). 


\subsection{Catalyst Testing}

The high-throughput facility allowed us to run 96 reactions in parallel for various catalyst compositions under the same concentrations and conditions $\left(100{ }^{\circ} \mathrm{C}, 18 \mathrm{~h}\right)$, including repetition of trials and blank experiments. Simple model substrates (1,2-diphenyl2-methoxyethanol (1) for the lignin $\beta$-O-4 linkage and meso-hydrobenzoin (2) for sugarderived polyalcohols) were chosen to test for selectivity towards $\mathrm{C}-\mathrm{O}, \mathrm{C}-\mathrm{C}$, or $\mathrm{C}-\mathrm{H}$ bond cleavage (Scheme 1). For substrate $\mathbf{1}$, the dipicolinate oxovanadium (V) catalyst, VOdipic, effects significant $\mathrm{C}-\mathrm{O}$ bond cleavage in DMSO, but exclusive $\mathrm{C}-\mathrm{H}$ bond activation in pyridine solvent, followed by $\mathrm{C}-\mathrm{C}$ bond cleavage of the resulting ketone [11]. In contrast, a homogeneous copper catalyst was shown to effect the direct $C-C$ bond cleavage of $\mathbf{1}$. With substrate 2 the VOdipic catalyst affords benzaldehyde along with $\mathrm{C}-\mathrm{H}$ bond activation products benzoin and benzil [11,12].

Initial high-throughput testing of our supported $\mathrm{V}$ catalysts was performed using acetonitrile as solvent at $100{ }^{\circ} \mathrm{C}$ for $18 \mathrm{~h}$, similar conditions to those used with the VOdipic homogeneous counterpart. Our results demonstrate that substrate $\mathbf{1}$ undergoes predominately direct $\mathrm{C}-\mathrm{C}$ bond cleavage even at high conversion without addition of a base (Table 2).

Table 2. High-throughput screening of 1,2-diphenyl-2-methoxyethanol oxidation using Al anchors.

\begin{tabular}{|c|c|c|c|c|c|}
\hline Catalysts & Conversion & - & Selectivity & $(\%)$ & - \\
\hline- & $(\%)$ & Benzaldehyde & Methyl Benzoate & Methanol & Benzoin Methyl Ether \\
\hline 1Al-MS-L-cal & 0 & - & - & - & - \\
\hline (1-1)VAl-MS-L-cal & 14 & 100 & 0 & 0 & 0 \\
\hline (2.5-1)VAl-MS-L-cal & 53 & 86 & 7 & 7 & 0 \\
\hline (5-1)VAl-MS-L-cal & 72 & 89 & 5 & 6 & 0 \\
\hline 2.5Al-MS-L-cal & 0 & - & - & - & - \\
\hline (2.5-2.5)VAl-MS-L-cal & 49 & 84 & 10 & 6 & 0 \\
\hline (5-2.5)VAl-MS-L-cal & 63 & 88 & 6 & 6 & 0 \\
\hline 5Al-MS-L-cal & 0 & - & - & - & - \\
\hline (1-5)VAl-MS-L-cal & 7 & 100 & 0 & 0 & 0 \\
\hline (2.5-5)VAl-MS-L-cal & 35 & 93 & 0 & 0 & 7 \\
\hline (5-5)VAl-MS-L-cal & 43 & 85 & 8 & 7 & 0 \\
\hline 10Al-MS-L-cal & 0 & - & - & - & - \\
\hline (1-10)VAl-MS-L-cal & 5 & 100 & 0 & 0 & 0 \\
\hline (2.5-10) VAl-MS-L-cal & 33 & 83 & 10 & 0 & 7 \\
\hline (5-10)VAl-MS-L-cal & 41 & 94 & 0 & 0 & 6 \\
\hline
\end{tabular}

\subsection{Product Analysis and General Selectivity Trends}

The main product obtained using the lignin model molecule, substrate $\mathbf{1}$, was always benzaldehyde, formed almost exclusively at low conversions (Table S6). This suggests that the fastest pathway proceeds by both $\mathrm{C}-\mathrm{O}$ and $\mathrm{C}-\mathrm{C}$ bond cleavage (Scheme 1, route a1). The production of methanol was difficult to measure precisely as this volatile molecule partially evaporates between the aperture of the well on cooling and subsequent sample analysis. One should keep in mind that the quantities to analyze are small as each reactor of the high-throughput systems contains $6 \mathrm{mg}$ of catalyst and $0.025 \mathrm{mmol}$ of substrate in $0.5 \mathrm{~mL}$ of acetonitrile. Under these conditions, the carbon mass balance could not be accurately determined, and conversion was estimated by the decrease in substrate concentration. Thus, the selectivity was calculated from the concentration of benzaldehyde produced according to routes $\mathrm{a}_{1}$ and $\mathrm{a}_{2}$, together with methyl benzoate, produced exclusively via route $\mathrm{a}_{2}$, taking into account the stoichiometry of the reactions involved (Scheme 1). It was observed for several catalysts that benzoin methyl ether, produced by $\mathrm{C}-\mathrm{H}$ bond cleavage of substrate 1, does not react further under our reaction conditions. Benzoin methyl ether and/or methylbenzoate systematically appeared at high conversions, both fingerprinting the less productive routes $\mathrm{a}_{2}$ and $\mathrm{a}_{3}$. In contrast to the homogeneous catalysts, no benzoic acid, from over-oxidation of benzaldehyde, was produced. 


\subsection{High-Throughput Catalytic Tests Using the Lignin Model}

No activity was measured in the catalysts free of vanadium showing that the anchor ions $\mathrm{Ti}^{I V}, A l^{I I I}, \mathrm{Zr}{ }^{I V}$, and $\mathrm{C} e^{I V}$ are not active for oxidative $\mathrm{C}-\mathrm{C}$ bond cleavage of $\mathbf{1}$. By contrast, the samples free of anchors and containing vanadium were active. For instance, 1V-MS-L-cal converted $21 \%$ of substrate $\mathbf{1}$ with $100 \%$ selectivity to benzaldehyde (route $\mathrm{a}_{1}$ ) though vanadium leaching was extensive, rendering reproducibility and recyclability problematic. In addition, conversion increased with increasing vanadium loading with a gain in activity per vanadium at high loading for all catalysts. Conversely, conversion decreased for a given vanadium loading when the loading in anchor ions increased. Both trends are illustrated for the $A I^{I I I}$ anchors in Table 2 and Figure $4 a$. It appears that the best effect is obtained for 1 and $2.5 \mathrm{~mol} \%$ of anchors, while highest productivity was obtained for $5 \mathrm{~mol} \%$ of vanadium. The most active catalyst (5-1)VAl-MS-L-cal exhibited a substrate conversion of $72 \%$ with an effective selectivity towards route $a_{1}$ of $89 \%$ (Figure $4 b$ ).
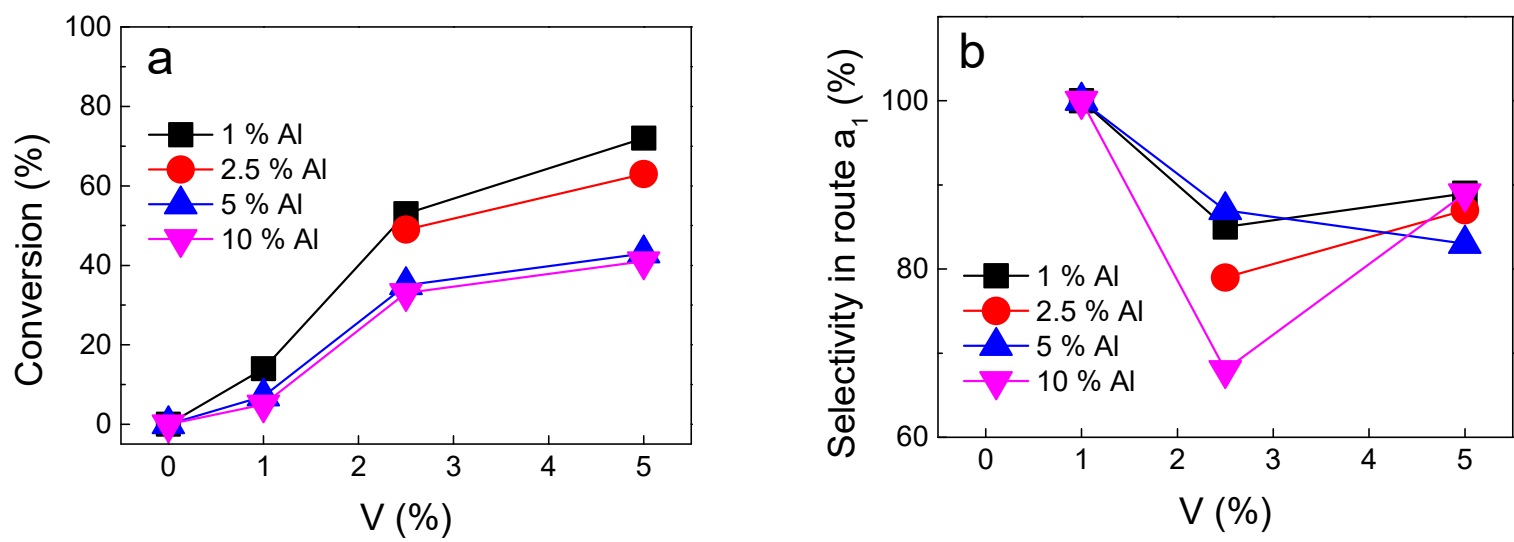

Figure 4. Loading effect of aluminum oxide anchors and anchored vanadium ions on conversion (a) and selectivity to route $\mathrm{a}_{1}(\mathbf{b})$ for VAl-MS-L-cal catalysts.

A similar trend was observed for the other anchor ions (Figure S10a-c). Note that samples (5-2.5)VZr-MS-L-cal and (5-1)VAl-MS-L-cal afforded a similar activity and selectivity for route $\mathrm{a}_{1}$ (Figure $5 \mathrm{a}$ and Figure S10b). Most of the differences come from the secondary selectivity (routes $\mathrm{a}_{2}$ and $\mathrm{a}_{3}$ ). Route $\mathrm{a}_{3}$ is disfavored over route $\mathrm{a}_{2}$ at high conversion for $\mathrm{Al}$ and eventually suppressed for conversion higher than $40 \%$. A similar trend was observed for Ti anchors (though less pronounced) as at $40 \%$ conversion the secondary selectivity was still near 50\% (Figure 6). For $\mathrm{Ce}$ and $\mathrm{Zr}$ anchors there are less data available for the comparison. Nonetheless, the effect of $\mathrm{Ce}$ anchors seems similar to that of $\mathrm{Al}$ as no benzoin methyl ether appeared at 50\% conversion.
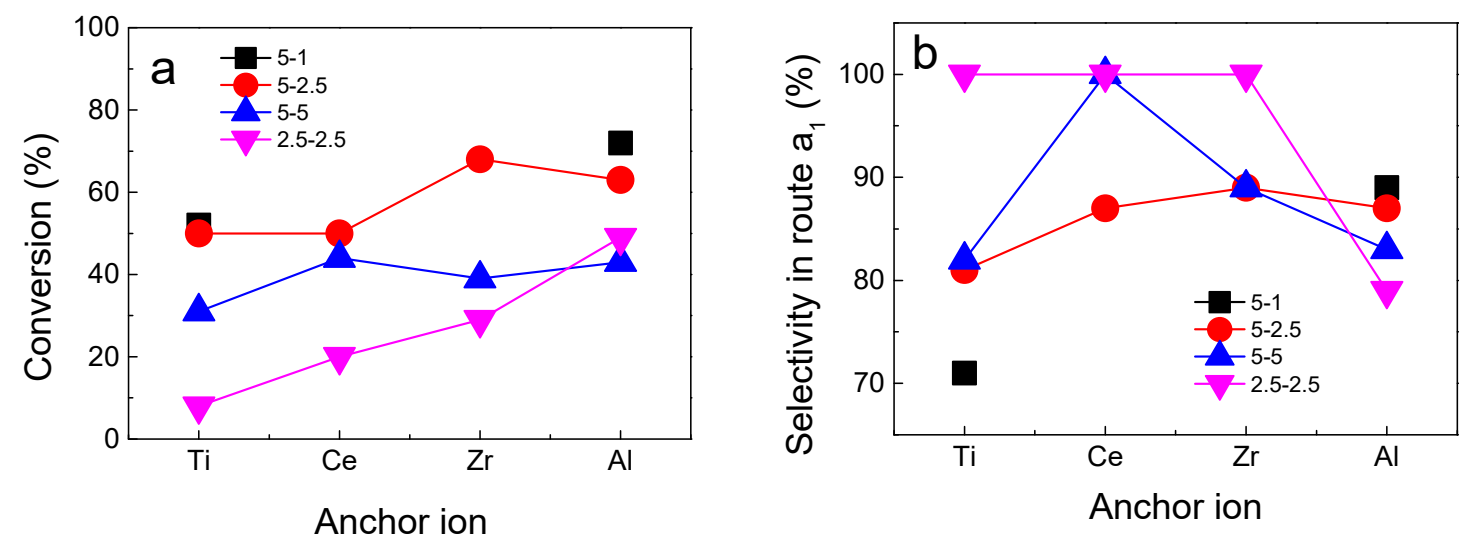

Figure 5. Effects of anchor type and metal loading on conversion (a) and selectivity to route $\mathrm{a}_{1}(\mathbf{b})$ for all the catalysts. (Symbols correspond to different $\mathrm{V}$ to $\mathrm{M}$ anchor ratios, (n-x)VM-MS-L/T-cal (M = Ti, Ce, Zr, and Al.) 


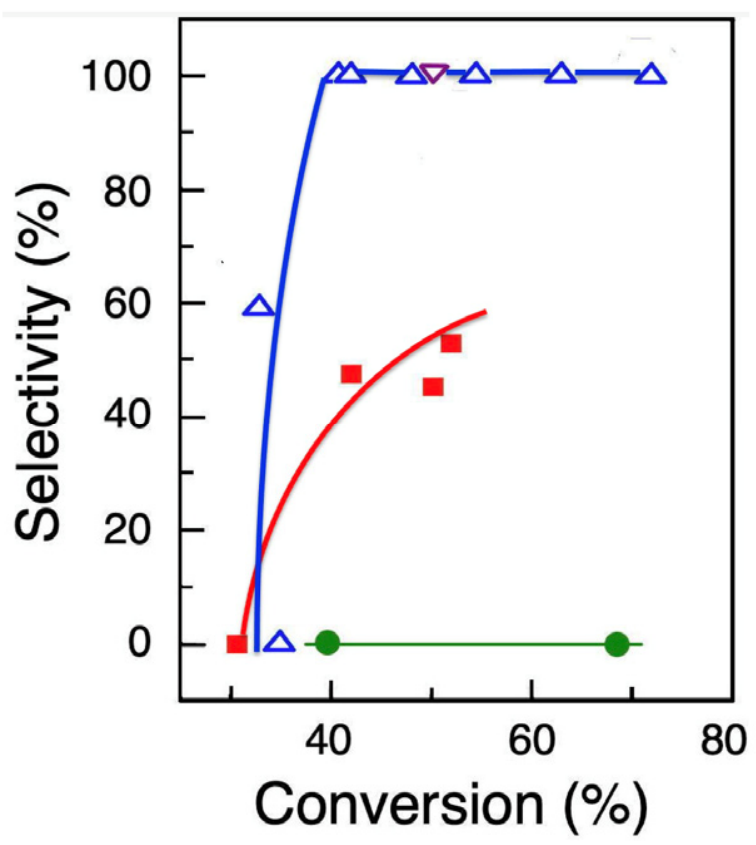

Figure 6. Selectivity to route $\mathrm{a}_{2}$ over route $\mathrm{a}_{3}$ versus conversion for different anchors and $\mathrm{V} / \mathrm{M}$ ratio of 2.5/2.5. (Green circles, red squares, blue upward triangles and purple downward triangles for $\mathrm{Zr}, \mathrm{Ti}, \mathrm{Al}$, and $\mathrm{Ce}$, respectively.) Excluded are samples containing $10 \mathrm{~mol} \% \mathrm{~V}$ and those with poor surface morphology.

Conversely, zirconium anchors favor definitively route $\mathrm{a}_{3}$ over $\mathrm{a}_{2}$ as no benzoin methyl ether was detected in the product distribution for conversions of 40 and $70 \%$ (Figure 6). This strongly suggests that benzoin methyl ether is not an intermediate to produce methyl benzoate but rather a dead-end product of route $\mathrm{a}_{3}$ exclusively. This is consistent with the absence of any color change of the catalysts nor any reaction of benzoin methyl ether under the same conditions used to transform substrate 1 or 2 (Figure S11, see details below).

The trend in conversion is consistent with catalytic activity derived from $2 \mathrm{D}$ vanadium rafts whatever the anchoring ions. Figure 5 provides a synopsis of all the sample properties for easiest cross-comparison between the catalysts. It shows that $\mathrm{Zr}$ anchors surpass $\mathrm{Al}$ regarding conversion only (Figures 5 and 6). Nonetheless, $\mathrm{Al}$ anchors give better yields for $\mathrm{C}-\mathrm{C} / \mathrm{C}-\mathrm{O}$ bond cleavage as they led to a complete course of route $\mathrm{a}_{2}$ (Scheme 1 ); thus, the ranking on total conversion of substrate 1 is $\mathrm{Zr} \geq \mathrm{Al}>\mathrm{Ce}>\mathrm{Ti}$. For total $\mathrm{C}-\mathrm{C}$ bond cleavage yield including routes $\mathrm{a}_{1}$ and $\mathrm{a}_{2}$ the ranking is $\mathrm{Al} \geq \mathrm{Zr}>\mathrm{Ce}>\mathrm{Ti}$. Looking specifically to route $\mathrm{a}_{2}$ where the capacity of the catalysts to cleave the C-C bond and operate a four-electron process, a third ranking can be proposed: $\mathrm{Ce} \sim \mathrm{Al}>\mathrm{Ti}>\mathrm{Zr}$. Note that ranking reactivity in the absence of anchors was ruled out as leaching is too extensive and a homogeneous route could not be excluded.

\subsection{Reactivity of Substrate 2: Testing Diol Internal C-C Bond Cleavage}

Commercially available substrate 2-meso-hydrobenzoin-was chosen as it can be converted into different products from $\mathrm{C}-\mathrm{C}$ bond cleavage-benzaldehyde-or $\mathrm{C}-\mathrm{H}$ bond cleavage-benzoin. The high-throughput reaction conditions were the same as those used for substrate $\mathbf{1}$. The most active catalysts for substrate $\mathbf{1}$ were those tested on substrate 2 (Table 3). All these catalysts exhibited 100\% selectivity to benzaldehyde, exhibiting exclusive $\mathrm{C}-\mathrm{C}$ bond cleavage in the aerobic oxidation of meso-hydrobenzoin in acetonitrile (Scheme 1, route b1). Their activity was systematically slightly higher than for substrate $\mathbf{1}$, the best being again (5-1)VAl-MS-L-cal. It is clear that having two vicinal OH functions favors the oxidative $\mathrm{C}-\mathrm{C}$ bond cleavage as observed with other catalysts [40]. In fact, pinacol, having two vicinal diol functions with no $\mathrm{C}-\mathrm{H}$ bond to cleave, gave selectively acetone with lower conversions of 55\%, 68\%, 66\%, and 38\% for (5-1)VTi, (5-1)VAl, (5-2.5)VZr, and 
(5-2.5)VCe-MS samples. This observation strongly suggests that chelation of the substrate favors $\mathrm{C}-\mathrm{C}$ bond cleavage.

Table 3. Conversion of meso-hydrobenzoin with vanadium stabilized by different anchors.

\begin{tabular}{cc}
\hline Catalysts & Conversion (\%) \\
\hline (5-1)VTi-MS-T-cal & 69 \\
(5-1)VAl-MS-L-cal & 82 \\
(5-2.5)VZr-MS-L-cal & 74 \\
(5-2.5)VCe-MS-T-cal & 77 \\
\hline
\end{tabular}

\subsection{Activity, Selectivity, and Vanadium Site Nuclearity}

The large set of data displayed here demonstrates that both changing the vanadium cluster nuclearity in the catalytic center and moving from one anchor to another affect both activity and $\mathrm{C}-\mathrm{C}$ vs. $\mathrm{C}-\mathrm{O}$ bond cleavage selectivity. While the origin of these trends may not be obvious at first sight, some correlations can be drawn. The first trend shows that lower optical gaps derived from the electronic spectra and Tauc plots are correlated with higher catalytic activity. This correlation is obtained here either by increasing the vanadium loading for a given anchor loading or by decreasing the anchor loading for a given vanadium loading. The dependence on the vanadium/anchor atomic ratio clearly demonstrates that the nuclearity of the oxohydroxo vanadium clusters changes during vanadium impregnation as vanadium precursors interact preferentially with anchors at low or high loading over a large span of vanadium to anchor $\mathrm{M}$ atomic ratios. This is true for each type of anchor as shown in Figures $4 \mathrm{a}$ and $5 \mathrm{a}$. Though the anchoring technique associated with incipient wetness impregnation adopted here for screening does not provide absolute molecular control on the site nuclearity, the activity threshold on vanadium loading (Figure $4 \mathrm{a}$ ) clearly suggests that mono- and dimeric oxovanadium sites are likely inactive. This is true also with the other anchors (Table 2, Table S6a,b) for which low loading and low vanadium to anchor $\mathrm{M}$ ratios lead to nearly inactive catalysts, depending on the nature of the anchors. Consistent with this nuclearity dependence, this activity threshold moves to higher vanadium loadings for higher anchor loading, especially for $\mathrm{Ti}, \mathrm{Zr}$, and $\mathrm{Ce}$ anchoring ions (Figure S10a-c). In discussing effects of the anchoring ion nature, it is important to note that, contrary to the other anchoring ions, aluminum ions are completely dispersed in the silica framework with some even embedded in the pore walls. Conversely, being less compatible with the $\mathrm{SiO}_{2}$ framework, $\mathrm{Ti}, \mathrm{Zr}$, and $\mathrm{Ce}$ ions tend to concentrate at the surface of the pore walls where they aggregate into larger oxohydroxo clusters at higher loadings. This is probably why aluminum is a much less effective anchor at low loading and much better at high loading where scarce anchors generate very active larger nuclearity sites.

Moving to selectivity, the low conversion catalysts, for which predominate formation of benzaldehyde is seen at low loadings, contain the smallest active sites, including probably trimers. The secondary pathways $\mathrm{a}_{2}$ and $\mathrm{a}_{3}$ are traversed by the larger, more active clusters. Note that pathway $\mathrm{a}_{2}$ to methyl benzoate is observed for $\mathrm{Zr}$ anchors only for the largest vanadium clusters obtained at higher loading and higher $\mathrm{V} / \mathrm{Zr}$ ratios. Pathway $\mathrm{a}_{3}$, involving $\mathrm{C}-\mathrm{H}$ cleavage as the primary step, is also triggered by larger clusters and is sensitive to the nature of the anchor. The data in Figure 6, taken for intermediary loadings and V/anchor ratios, allow us to emphasize these differences, showing how to choose the best composition to bypass pathway $a_{2}$ over $a_{3}$ or vice versa ( $c f . V /$ anchor $=2.5 / 2.5$, Figure 6 ).

In addition to the selectivity that advocates for a true heterogeneous catalytic pathway, the type of solvent required is another parameter supporting this assumption.

\subsection{Solvent Screening for Catalyst Comparison and Vanadium Leaching Test}

The oxidation of $\mathbf{1}$ was run in different solvents using one of the best vanadium catalysts, (5-1)VAl-MS-L-cal. Conversion was highest in weakly polar solvents-chloroform, benzene and EtOAc (Figure 7, Table S7, solvents 1-3). The selectivity towards direct 
$\mathrm{C}-\mathrm{O} / \mathrm{C}-\mathrm{C}$ bond cleavage was highest in EtOAc, toluene, and $\mathrm{MeCN}$, as revealed by the high yield of benzaldehyde (Figure 8, solvents 3-5). EtOAc being non-toxic, easy to handle, recyclable, and therefore the most sustainable, is thus the best solvent among those tested here. By comparison, $\mathrm{MeCN}$, enabling intermediate catalytic conversions and reasonably good selectivity, is better suited to compare the catalysts in high-throughput tests (Figure 8, solvent 5). Polar aprotic solvents like dimethylsulfoxide (DMSO), tetrahydrofuran, and dioxane were rather poor, leading to low conversions (15 to 30\%) while keeping a reasonably high selectivity to direct $\mathrm{C}-\mathrm{O} / \mathrm{C}-\mathrm{C}$ bond cleavage (50 to $70 \%$ benzaldehyde in the product distribution). In contrast to the homogeneous variants, the heterogeneous catalysts are basically inactive in pyridine, even for $\mathrm{C}-\mathrm{H}$ bond cleavage. Note also that the worst solvents were ethanol and water, i.e., protic solvents. Methanol, a polar and protic solvent was intentionally used for the leaching tests as it is the best solvent to extract weakly held vanadium ions without destroying the mesostructure of the silica support [20].

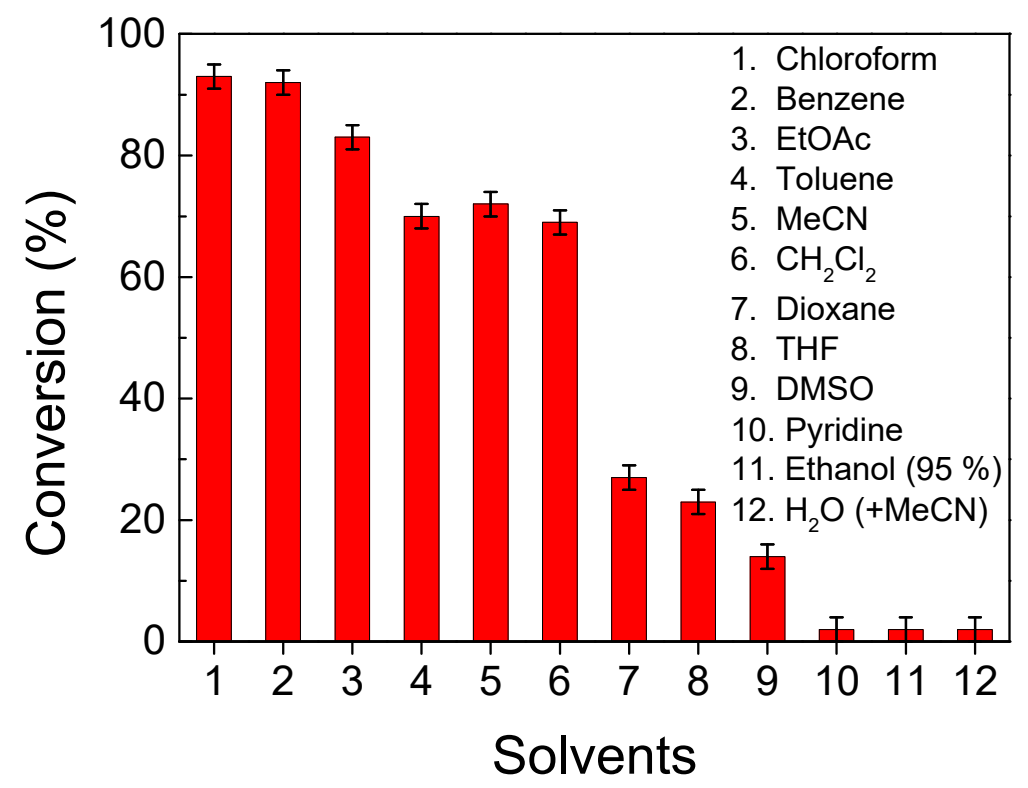

Figure 7. Conversion of 1,2-diphenyl-2-methoxyethanol in different solvents via (5-1)VAl-MS-L-cal catalyst. (Solvent number corresponds to the solvent list in Table S7).

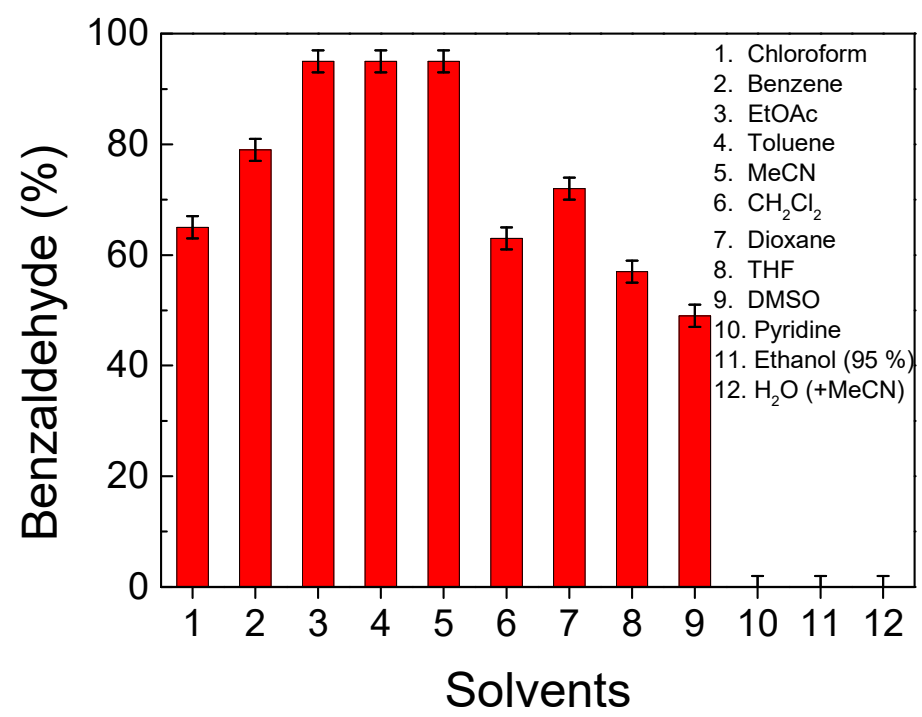

Figure 8. Solvent-dependent benzaldehyde product distribution using (5-1)VAl-MS-L-cal as catalyst (Table S7). 


\subsection{Leaching Test and Recyclability}

The rate of leaching was obtained for (2.5-2.5)VAl-MS-L-cal catalysts by elemental analysis carried out before and after the leaching test (Table 1). First, it appeared that there was almost no leaching of anchor ions, which confirms the strong linkage of the anchors with the silica surface. Second, vanadium retention on the pure silica support is weak as shown by the $70 \%$ vanadium loss in the $1 \mathrm{~V}$-MS-L-cal catalyst. Third, the $\mathrm{Al}$ and $\mathrm{Zr}$ anchors improve the retention of vanadium as the loss is limited to about $50 \%$. In comparison, Ti and Ce anchors lead to the strongest anchor effect as the loss dropped to about $20 \%$. These observations are in full agreement with catalysts prepared using conventional autoclaving, which further validates our choice of the fast synthesis route for the high-throughput investigation [20].

A second leaching test was performed on the same catalyst, (2.5-2.5)VAl-MS-L-cal, in the solvent used in the high throughput reaction test, namely, acetonitrile (see above). Harsher conditions were chosen to match those of the high-throughput test, i.e., $100{ }^{\circ} \mathrm{C}$ for $18 \mathrm{~h}$. Elemental analysis carried out before and after the test revealed that only $11 \%$ of $\mathrm{V}$ and $4 \%$ of $\mathrm{Al}$ had leached out. This is much smaller than in methanol. It shows that the worse solvents for the reaction are those leaching out more vanadium. Note that the best solvent, ethyl acetate, is expected to be even less detrimental to vanadium retention as it is a poor ligand.

The recycling test was performed on sample (2.5-5)VAl-MS-L-cal recovered by filtration and drying steps, and put back into the reaction using molecule 1 under the same reaction conditions (Table S8). The activity was slightly lower after each run with a total loss of $20 \%$ after the 4 th run (Figure 9). This is still higher than the conversion of the same sample that underwent leaching in methanol. This clearly demonstrates that leaching is greatly reduced under our reaction conditions. These observations also suggest that the catalytic activity is not correlated with the leached species, prompting us to investigate further the correlation between anchoring and reactivity.

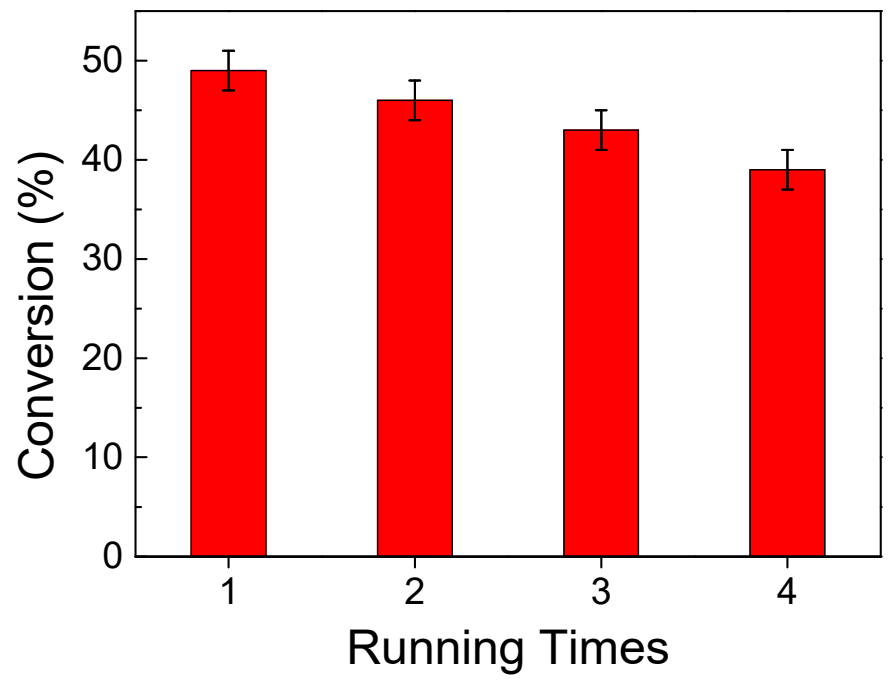

Figure 9. Catalytic recycling performance of (2.5-2.5)VAl-MS-L-cal catalyst to convert substrate 1 in acetonitrile.

\subsection{Mechanistic Considerations}

Addition of a radical trap (TEMPO) or bases (triethylamine or $N$-ethyldiisopropylamine) decreased the activity by $\sim 30$ or $\sim 40 \%$, respectively, when the anchors were $A l^{I I I}$ ions. The activity dropped further when the anchors were $\mathrm{Zr}$ ( $\sim 60$ or $\sim 95 \%$, respectively). This suggests that the vanadium-based heterogeneous catalysts are not proceeding via a radical mechanism (Fenton like) like iron-based catalytic oxidation [40] nor by the base-assisted mechanism employed by homogeneous catalysts [41]. The appearance of paramagnetic V(III) and V(IV) ions (that would possibly fingerprint a one-electron process), was observed only in minute traces in the EPR spectra after reaction completion or after quenching the reaction after 
$1 \mathrm{~h}$. After quenching at the beginning of the reaction, the EPR signal is rather broad and could fit with a V(III) species or with two weakly interacting V(IV) ions inside a 2D raft of vanadium ions, likely produced by a $\mathrm{V}(\mathrm{III})-\mathrm{V}(\mathrm{V})$ amphoterization. In fact, the redox involvement of vanadium in the process is characterized by a green color and an absorption band at $\sim 600 \mathrm{~nm}$ both typical of V(III) ions instead of a blue color and an absorption at about $800 \mathrm{~nm}$ (Figure S11). These last observations, together with the optimal solvent being ethyl acetate, the specific selectivity for direct $\mathrm{C}-\mathrm{C}$ bond cleavage via route $\mathrm{a}_{1}$, the specificity of some anchors to favor route $\mathrm{a}_{2}$ over route $\mathrm{a}_{3}$, and the low vanadium leaching suggest that the present catalysts operate via a true heterogeneous process, the mechanism of which differs from that adopted by the homogeneous oxovanadium catalysts.

\subsection{Catalytic Cycle}

From the above observations, it is clear that the heterogeneous catalytic $\mathrm{C}-\mathrm{C}$ bond cleavage pathway observed herein differs considerably from those proposed using molecular oxovanadium catalysts. Most important is the non-Fenton like route, excluding radical intermediates or single electron transfer coupled to single oxygen transfer that implies a +4 oxidation state of vanadium being marginal in comparison to the +3 oxidation state, according to UV-visible spectroscopy [42]. Instead, a two-electron transfer is likely to take place. This is consistent with the direct reduction of molecular $V(V)$ complexes in the presence of alcohol [43]. The other striking observation is the production of methylbenzoate via route $\mathrm{a}_{2}$, as it is a four-electron pathway. The presence of a deep green color at the end of the reaction that disappears slowly after exposing the catalysts to air at room temperature is evidence that the aerobic oxidation of $\mathrm{V}(\mathrm{III})$ to $\mathrm{V}(\mathrm{V})$ is a slow process in the catalytic cycle. The latter requires a substrate able to reduce the $\mathrm{V}(\mathrm{V})$ oxo into $\mathrm{V}(\mathrm{III})$ concomitantly with an oxygen atom transfer and two electrons (formally $\mathrm{O}^{2-}$ ) from the metal to the substrate, producing a $\mathrm{V}(\mathrm{III})$ ion (step 1 of the cycle, Scheme 2-insert). Then, $\mathrm{V}(\mathrm{V})$ peroxo is produced by adsorption of dioxygen molecule (Step 2, Scheme 2-insert). The $\mathrm{V}(\mathrm{V})$ oxo is regenerated from the $\mathrm{V}(\mathrm{V})$ peroxo complex assuming a second oxygen transfer from the peroxo ligand to the substrate, concomitantly with a $\mathrm{C}-\mathrm{H}$ cleavage (step 3, Scheme 2-insert). Apparently, methane oxidation into formaldehyde on silica supported $\mathrm{Mn}(\mathrm{V})$ oxo species proceeds also via the oxo-peroxo redox catalytic cycle, a hypothesis supported by DFT calculations [44,45].

The successful $\mathrm{V}(\mathrm{V})$ oxo site presumably allows coordination of the substrate, facilitating the "inner sphere" oxygen atom transfer process. Our results suggest that larger clusters are necessary to create these reducible active sites. The four-electron process of route $\mathrm{a}_{2}$ can be rationalized by assuming that the substrate undergoing the first oxygen transfer after reduction of the oxo complex stays in the coordination sphere of the V(III) ions during the reoxidation of $\mathrm{V}(\mathrm{III})$ into the $\mathrm{V}(\mathrm{V})$ peroxo species. Alternatively, the hemiacetal that may desorb after $\mathrm{C}-\mathrm{C}$ bond cleavage, according to route $\mathrm{a}_{1}$, may readsorb on the $\mathrm{V}$ (III) species before reoxidation into $\mathrm{V}(\mathrm{V})$ peroxo species. This may explain why route $\mathrm{a}_{2}$ is favored at high conversion. The presence of route $\mathrm{a}_{3}$, not specified in Scheme 1 , is likely to take place after desorption of the hemiacetal and reoxidation of the $\mathrm{V}$ (III) species into a substrate free $V(V)$ peroxo. Indeed, reacting hydrobenzoin methyl ether (substrate $\mathbf{1}$ ) with this peroxo intermediate would lead to benzoin methyl ether via route $\mathrm{a}_{3}$. Note that the present oxo-peroxo mechanism requires a substrate able to reduce $\mathrm{V}(\mathrm{V})$ to $\mathrm{V}(\mathrm{III})$ ions at moderate temperature $\left(100^{\circ} \mathrm{C}\right)$ with no need for reducible anchoring ions. This is the reason why the reducibility of the $\mathrm{V}$ oxo species has to be increased by clustering, reaching the appropriate size of $\mathrm{V}_{\mathrm{x}} \mathrm{O}_{\mathrm{y}}$ cluster, which indeed correlates with the variation of the optical gap, a correlation shown to operate nicely for many different mixed oxide catalysts active in oxydehydrogenation of propane $[37,46]$. However, the absence of a route leading to benzoic acid indicates that diols cannot undergo a second oxidation process on the vanadium site. The propensity of diol to act as a bidentate ligand blocking the complexation of dioxygen as a peroxo ligand may explain why this route is blocked. Thorough investigation on diol oxidation using these catalysts would be necessary to consolidate this hypothesis. 


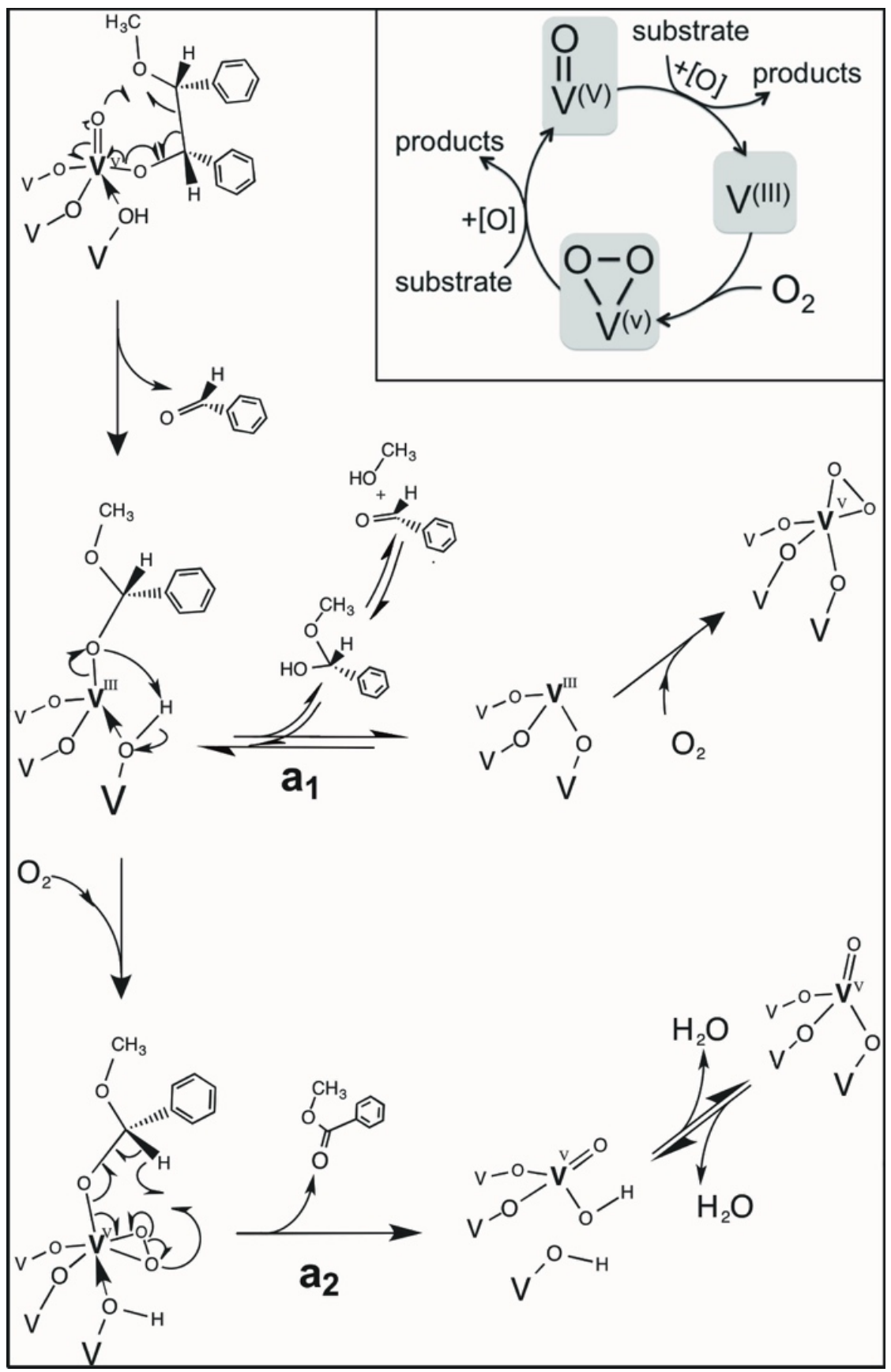

Scheme 2. Proposed concerted redox mechanism for some of the catalytic steps and a common initial step corresponding to formation of an adsorbed hemiacetal intermediate; route $\mathrm{a}_{1}$ results from desorption of the hemiacetal, while route $\mathrm{a}_{2}$ results from a second oxidation step after adsorption of a dioxygen molecule; route $a_{3}$-not specified in the scheme-would proceed from substrate 1 reacting with free $\mathrm{V}(\mathrm{V})$ peroxo species produced from route $\mathrm{a}_{2}$. Insert: vanadium catalytic cycle assuming a single site on grafted $2 \mathrm{D} \mathrm{VO}_{\mathrm{x}}$ rafts; oxygen atom transfer from the $\mathrm{V}(\mathrm{V})$ oxo to substrate is followed by aerobic oxidation of $\mathrm{V}(\mathrm{III})$ to $\mathrm{V}(\mathrm{V})$ peroxo that transfers a second oxygen to substrate, regenerating the $\mathrm{V}(\mathrm{V})$ oxo.scheme 2.

The complete insensitivity to redox-active anchors like Ti(IV) or Ce(IV) and the relatively low temperature suggests that there is no need for the formation of oxygen vacancies and, instead, the reoxidation pathway occurs via a peroxo species. This is in contrast to the Mars-van Krevelen mechanism [47,48]. 


\section{Conclusions}

Mesoporous silica-supported vanadium catalysts with different $\mathrm{Ti} / \mathrm{Al} / \mathrm{Zr} / \mathrm{Ce}$ anchor ions were obtained by direct synthesis using rapid microwave-assisted autoclaving, allowing us to vary both the vanadium and anchor-ion loadings. The hexagonal honeycomb structure of the mesoporous silica is maintained for total metal loadings less than $10 \mathrm{~mol} \%$ $(\mathrm{V}+$ anchor $) / \mathrm{Si}$. Nonetheless, specific surface area, pore volume, and pore diameter decreased with higher metal loading. After calcination, the organic template was removed and the $V^{I V}$ precursor was oxidized to $V^{V}$ ions. The LMCT bands of $V^{V}$ ions, measured by diffuse reflectance UV-vis spectra, were blue-shifted in the presence of the anchor ions, indicating a better dispersion of vanadium. Ti anchors were the best and a ranking with the other anchors was delineated. The large set of catalyst compositions generated in the present study allowed us to show that vanadium dispersion systematically increases for higher anchor to vanadium ratios, for all anchoring ions. A comparison of their optical gaps with reference compounds, showed that this dispersion varies from grafted 2D rafts to isolated $\mathrm{V}$ species.

The novel anchoring process described above allowed for the rare observation of oxidative $\mathrm{C}-\mathrm{C}$ bond cleavage in simple lignin and sugar polyalcohol models using a heterogeneous $\mathrm{V}$ catalyst. At $100{ }^{\circ} \mathrm{C}$ in "green" ethyl acetate solvent, the vanadium catalysts showed excellent selectivity for direct $\mathrm{C}-\mathrm{C}$ bond cleavage at the $\beta-\mathrm{O}-4$ or internal diol position. The robustness of the catalysts upon recycling was good for all the anchors. The samples with a higher loading of vanadium active sites and a 2D raft organization of the $\mathrm{V}$ species exhibited the highest substrate conversion, with the $\mathrm{Al}$ anchor ions inducing the highest activity. Basic media, known to promote the homogeneous catalytic pathway, were detrimental to the activity of these heterogeneous catalysts. All these data are consistent with a true heterogeneous pathway that differs from the homogeneous one and takes place preferably on grafted $2 \mathrm{D} \mathrm{VO}_{\mathrm{x}}$ rafts. Of particular note is the absence of over-oxidation to carboxylic acid and the surprising lack of reactivity of benzoin methyl ether. The catalytic C-C bond cleavage of 1,2-diphenyl-2-methoxyethanol is more difficult than that for meso-hydrobenzoin diol, but easier than pinacol, a diol without nearby aryl groups, that better models sugar derivatives. The existence of the peroxo intermediate will be tested using alkene substrates for possible epoxidation reactions. More complex lignin models will also be tested, including phenolic models that may yield quinones from $\mathrm{C}_{\mathrm{aryl}}{ }^{-} \mathrm{C}$ bond cleavage $[10,12]$.

\section{Materials and Methods}

\subsection{General}

All operations were conducted in air unless otherwise specified. All reagents and solvents were used as received without further purification: Ludox ${ }^{\circledR}$ HS-40 colloidal silica (Sigma-Aldrich, St. Louis, MO, USA, $40 \mathrm{wt} \%$ in $\mathrm{H}_{2} \mathrm{O}$ ), cetyltrimethylammonium p-toluenesulfonate (CTATos, Acros, Fair Lawn, NJ, USA, >99\%), tetramethylammonium hydroxide (TMAOH, Alfa Aesar, Haverhill, MA, USA, $25 \mathrm{wt} \%$ in $\mathrm{H}_{2} \mathrm{O}$ ), tetraethyl orthosilicate (TEOS, Sigma-Aldrich, 98\%), tetrabutyl orthotitanate (TBOT, Alfa Aesar, $>99 \%$ ), vanadium (IV) sulfate oxide hydrate (Alfa Aesar, 99.9\%), zirconium (IV) oxynitrate hydrate (Alfa Aesar, 99.9\%), cerium (III) acetylacetonate hydrate (Sigma-Aldrich, >99\%), aluminum sulfate hydrate (Sigma-Aldrich, 98\%), sodium hydroxide (Acros, 98\%), benzoin methyl ether (Alfa Aesar, 97\%), meso-hydrobenzoin (Sigma-Aldrich, 99\%), 2,2,6,6-tetramethyl-1piperidinyloxy (TEMPO, Sigma-Aldrich, 98\%), triethylamine (TEA, Sigma-Aldrich, >99\%), N-ethyldiisopropylamine (EDPA, Sigma-Aldrich, $>98 \%$ ), sodium borohydride (SigmaAldrich, $>96 \%$ ), ammonium chloride (Sigma-Aldrich, $>99.5 \%$ ), and mesitylene (SigmaAldrich, $>99.8 \%$ ). Solvents were dried using molecular sieves if needed.

A 1450 W Berghof Speedwave microwave oven $(2450 \mathrm{MHz})$ with Teflon autoclaves was used for the synthesis of the materials. Chemical analyses were performed by CREALINS in Lyon, France. Infrared spectra were recorded on a JASCO FT/IR-4200 spectrometer (Lisses, France) with ATR PRO470-H accessory. Thermogravimetric analyses (TGA) were 
performed with a NETZSCH STA 409 PC Luxx device (Selb, Germany) under aerobic conditions with a $10{ }^{\circ} \mathrm{C} / \mathrm{min}$ temperature ramp. Nitrogen sorption isotherms at $77 \mathrm{~K}$ were performed with a Belsorp Marx volume device (Microtrac, York, PA, USA) on solids that were dried under vacuum overnight at $130^{\circ} \mathrm{C}$. Low-angle X-ray powder diffraction (XRD) was performed using a Bruker (Siemens) D5005 diffractometer (Billerica, MA, USA) with Cu $\mathrm{K} \alpha$ monochromatic radiation. EPR spectra were recorded on a Bruker Elexsys e500 X-band (9.4 GHz) spectrometer with a 4102ST cavity. TEM images were recorded on an FEI G2F30 Tecnai $^{\mathrm{TM}}$ transmission electron microscope (Hillsboro, OR, USA), the accelerating voltage was $300 \mathrm{kV}$, and the crystallographic image processing on HRTEM images was carried out with the CRISP program. Solid UV-visible spectra were measured using a JASCO V-670 spectrophotometer in diffuse reflectance mode. Solid-state NMR spectra were measured on the Avance III Bruker $500 \mathrm{MHz}$ Wide Bore spectrometer, with a CP/MAS DVT (double resonance, variable temperature) $4 \mathrm{~mm}$ probe. The delay time between pulses (pulse width $5 \mu \mathrm{s}$ ) in HPDEC experiments was set to $500 \mathrm{~s}$. Spinning speed was set to $\sim 5 \mathrm{kHz}$ and the number of scans was 5000. Frequency ${ }^{13} \mathrm{C}=125.8 \mathrm{MHz},{ }^{29} \mathrm{Si}=99.4 \mathrm{MHz}$. Gas chromatography analysis was carried out by an Agilent Technologies 6850 Series II Network GC System (Santa Clara, CA, USA). Column: Restek RTX-1, $30 \mathrm{~m} \times 320 \mu \mathrm{m} \times 0.25 \mu \mathrm{m}$. Inlet: $50: 1,250{ }^{\circ} \mathrm{C}, 10.9 \mathrm{psi}$. Temperature program: $55^{\circ} \mathrm{C}$ for $2 \mathrm{~min}$, ramp $\left(35^{\circ} \mathrm{C} / \mathrm{min}\right)$ to $150{ }^{\circ} \mathrm{C}$ and hold for $1 \mathrm{~min}$, then $\operatorname{ramp}\left(35^{\circ} \mathrm{C} / \mathrm{min}\right)$ to $200^{\circ} \mathrm{C}$ and hold $1.25 \mathrm{~min}$, finally ramp $\left(35^{\circ} \mathrm{C} / \mathrm{min}\right)$ to $275^{\circ} \mathrm{C}$ and hold for $3.25 \mathrm{~min}$. High-throughput catalyst testing was performed on Unchained Lab's Freeslate system (Pleasanton, CA, USA) using the SV-vial technology. Reactions were conducted in $1.2 \mathrm{~mL}$ glass shell vials equipped with parylene-coated stir bars in 96-well aluminum plates which were sealed with a PFA sheet, rubber gasket, and top stainless steel plate.

\subsection{Synthesis}

4.2.1. Preparation of Mesoporous Silica MS (MS = Microwave Synthetic Mesoporous Silica)

The mesoporous silica MS-L was prepared as already described using Ludox (40 $\mathrm{wt} \%$ ) as silica source, cetyltrimethylammonium tosylate (CTATos) as template, and microwave heating [1]. The molar composition of the gel was $1 \mathrm{SiO}_{2} / 0.05 \mathrm{CTATos} / 0.5 \mathrm{NaOH} / 80 \mathrm{H}_{2} \mathrm{O}$. A 1 min-ramp microwave heating from room temperature to $180^{\circ} \mathrm{C}$ was used and then heating at $180^{\circ} \mathrm{C}$ for $9 \mathrm{~min}$. The surfactant was removed by calcination in a tube furnace with flowing air. The obtained white powder was named MS-L-cal. The calcination program was set as follows: $2^{\circ} \mathrm{C} / \mathrm{min}$ ramp from room temperature to $550^{\circ} \mathrm{C}$, then heating at $550{ }^{\circ} \mathrm{C}$ for $6 \mathrm{~h}$, and cooling down in air.

\subsubsection{Preparation of $1 \mathrm{~V}-\mathrm{MS}-\mathrm{L}$}

1V-MS-L was prepared in a similar way as MS-L except that vanadyl sulfate was dissolved in water together with the CTATos solution at $60^{\circ} \mathrm{C}$, obtaining a clear blue viscous solution. When the surfactant solution was mixed with the $\mathrm{Na}_{2} \mathrm{SiO}_{3}$ solution, the color of this mixture turned from light blue to dark green. The gel molar composition was $1 \mathrm{SiO}_{2} / 0.05$ CTATos/0.5 NaOH/80 $\mathrm{H}_{2} \mathrm{O} / 0.01 \mathrm{VOSO}_{4}$. After heating in the microwave reactor and filtration, the solid was pale green while the filtrate was light yellow. The as-made pale green powder was named 1V-MS-L, and after calcination 1V-MS-L-cal. 1V indicates the 1 molar\% of vanadium relative to silicon in the initial gel. (Elemental analysis of real vanadium relative to silicon is 0.7 molar $\%$.)

\subsubsection{Preparation of VTi-MS-T}

Solution A: $25.52 \mathrm{~g}$ of tetramethylammonium hydroxyde (TMAOH, $25 \mathrm{wt} \%$ ) was dissolved in $90 \mathrm{~g}$ of deionized water, then $41.66 \mathrm{~g}$ of tetraethoxysilane (TEOS) was added dropwise under stirring. The mixture was stirred at room temperature overnight until it was clear. Solution B: $0.68 \mathrm{~g}$ of tetrabutyl orthotitanate (TBOT) was dissolved in $25 \mathrm{~mL}$ isopropanol. Solution C: solution B was added dropwise to solution A with stirring at $0{ }^{\circ} \mathrm{C}$. The mixture was stirred at $0{ }^{\circ} \mathrm{C}$ until clear, then solution $\mathrm{C}$ was separated into 4 aliquots, each containing about $44.5 \mathrm{~g}$. 
Solution D: four surfactant solutions were prepared in parallel, i.e., D1, D2, D3, and D4. Each one contained $2.05 \mathrm{~g}$ CTATos dissolved in $44.8 \mathrm{~g}$ deionized water and stirred at $60{ }^{\circ} \mathrm{C}$ for $1 \mathrm{~h}$. Solution D1 was a clear surfactant solution without additional vanadyl sulfate. Vanadyl sulfate $(0.106 \mathrm{~g}, 0.266 \mathrm{~g}$, and $0.531 \mathrm{~g})$ was added in solutions D2, D3, and D4 separately, and stirred for another $1 \mathrm{~h}$ at $60{ }^{\circ} \mathrm{C}$.

Solution C (44.5 g) of was then added dropwise to solution D1 and stirred at $60{ }^{\circ} \mathrm{C}$ for $2 \mathrm{~h}$. The gel molar composition was: $1 \mathrm{SiO}_{2} / 0.09 \mathrm{CTATos} / 0.35 \mathrm{TMAOH} / 80 \mathrm{H}_{2} \mathrm{O} / \mathrm{xTiO}_{2}$ $(x=0.01 / 0.025 / 0.05 / 0.10)$. After heating in the microwave reactor, filtration and drying overnight, the white solid obtained was named as 1Ti-MS-T $(x=0.01)$, and after calcination (to remove the surfactant) 1Ti-MS-T-cal. In the case of solutions D2, D3, and D4, 44.2 $\mathrm{g}$ of solution $C$ was added to each solution and the same preparation was performed, obtaining the solids (1-1)VTi-MS-T-(-cal), (2.5-1)VTi-MS-T(-cal), and (5-1)VTi-MS-T(-cal), respectively.

\subsubsection{Preparation of VAl-MS-L}

Aluminum sulfate was chosen as the Al source. The preparation procedure was similar that for V-MS-L(-cal). The only difference was that, before the addition of vanadyl sulfate, aluminum sulfate was added to the surfactant solution (2 times the CTATos concentration compared to the ratio for synthesis V-MS-L). After $1 \mathrm{~h}$ of stirring at $60{ }^{\circ} \mathrm{C}$, $\mathrm{VOSO}_{4}$ was added and stirred for another $1 \mathrm{~h}$ at $60^{\circ} \mathrm{C}$. The gel molar composition was $1 \mathrm{SiO}_{2} / 0.1$ CTATos/0.5 NaOH/80 $\mathrm{H}_{2} \mathrm{O} / \mathrm{x} \mathrm{Al}_{2} \mathrm{O}_{3} / \mathrm{n} \mathrm{VOSO}_{4}(\mathrm{x}=0.005 / 0.125 / 0.25 / 0.05$, $\mathrm{n}=0.00 / 0.01 / 0.025 / 0.05)$. The products were named (100n-200x)VAl-MS-L(-cal).

\subsubsection{Preparation of VZr-MS-L and VZr-MS-L}

The synthesis of VZr-MS-L was the same as that of V-MS-L(-cal), using $\mathrm{ZrO}\left(\mathrm{NO}_{3}\right)_{2}$ as $\mathrm{Zr}$ source. The only difference was that, before the addition of vanadyl sulfate, $\mathrm{ZrO}\left(\mathrm{NO}_{3}\right)_{2}$ was added into the surfactant solution ( 2 times the CTATos concentration compared to the ratio for the synthesis of V-MS-L) and stirred $1 \mathrm{~h}$ at $60{ }^{\circ} \mathrm{C}$. Then, $\mathrm{VOSO}_{4}$ was added and stirred an additional hour at $60{ }^{\circ} \mathrm{C}$. The gel molar composition was $1 \mathrm{SiO}_{2} / 0.1 \mathrm{CTATos} / 0.5 \mathrm{NaOH} /$ $80 \mathrm{H}_{2} \mathrm{O} / \mathrm{x} \mathrm{ZrO}_{2} / \mathrm{n} \mathrm{VOSO}_{4}(\mathrm{x}=0.025 / 0.05, \mathrm{n}=0.00 / 0.01 / 0.025 / 0.05)$. The products were named (100n-100x)VZr-MS-L(-cal).

\subsubsection{Preparation of VCe-MS-T}

VCe-MS-T were synthesized as for VZr-MS-T. Cerium(III) acetylacetonate hydrate was used as Ce source and TEOS was used as Si source, the gel molar composition was $1 \mathrm{SiO}_{2} / 0.09$ CTATos /0.35 TMAOH/80 H $\mathrm{H}_{2} \mathrm{O} / 0.025 \mathrm{CeO}_{2} / \mathrm{n} \mathrm{VOSO}_{4}(\mathrm{n}=0.00 / 0.01 / 0.025 / 0.05)$ and the products were named (100n-2.5)VCe-MS-T(-cal).

4.2.7. Synthesis of Lignin Model 1,2-Diphenyl-2-methoxyethanol ( $\beta$-Methoxy- $\alpha$-phenylphenethyl Alcohol)

1,2-Diphenyl-2-methoxyethanol ( $\beta$-methoxy- $\alpha$-phenylphenethyl alcohol) was synthesized by reduction of benzoin methyl ether using the method of Hanson [10]. Benzoin methyl ether $(3.06 \mathrm{~g}$ ) was dissolved in $50 \mathrm{~mL}$ dry ethanol and stirred at room temperature until clear. Then, sodium borohydride ( $2.03 \mathrm{~g}$ ) was slowly added (to control $\mathrm{H}_{2}$ evolution rate) and the resulting mixture was stirred at room temperature. After refluxing at $85{ }^{\circ} \mathrm{C}$ overnight, the solution was cooled in an ice bath. Then, $50 \mathrm{~mL}$ of a saturated solution of ammonium chloride was slowly added and the mixture was stirred for $1 \mathrm{~h}$. Diethyl ether was added to the mixture and the solid was removed by filtration. The organic phase was extracted, washed 3 times with $\mathrm{H}_{2} \mathrm{O}$, and then twice with $0.1 \mathrm{M} \mathrm{HCl}$. After removing the solvent with a rotary evaporator, the colorless solid product $(\sim 3 \mathrm{~g})$ was obtained and purity confirmed by ${ }^{1} \mathrm{H}$ NMR.

\subsection{Catalytic Tests Using High-Throughput Screening (HTS)}

Oxidation reactions of the lignin model were carried out in the high-throughput experimentation facility in the Centre for Catalysis Research and Innovation at the University of Ottawa. The reactions were conducted in $1 \mathrm{~mL}$ glass vials with each reactor plate holding 
96 vials. In order to prepare the samples for the reaction, $6 \mathrm{mg}$ of vanadium-supported catalyst was weighed and carefully introduced into each vial that was equipped with a magnet rotor. Then, $0.5 \mathrm{~mL}$ of substrate solution (with $25 \mathrm{mmol} / \mathrm{L}$ mesitylene as internal standard and $50 \mathrm{mmol} / \mathrm{L}$ substrate) was injected. The reactors were covered by a polyfluoroalkoxy copolymer resin (PFA) membrane and closed tightly to hold the pressure during the reaction. After stirring at $100{ }^{\circ} \mathrm{C}$ for $18 \mathrm{~h}$, the reactor plate was cooled to room temperature. The mixture in the reactors was taken out, filtered, and washed with acetonitrile separately. Then, the solution was taken for analysis by gas chromatography. Substrate conversion was calculated by comparing the concentration of remaining substrate vs. total concentration of products using their experimentally determined response factors. Product selectivities in Table 2 were calculated as a percentage of total products. Pathway selectivities were calculated from product selectivities taking into account that pathway a produces as much as methyl benzoate (MB) as benzaldehyde (BA) that should not be taken into account for the selectivity calculation for pathway $a_{1}$. Nevertheless, MB traces only pathway $a_{2}$, just as benzoin methyl ether (BME) comes only from pathway $\mathrm{a}_{3}$. Therefore, the selectivities are calculated as follows: $\mathrm{Sa}_{1}=\left(\mathrm{S}_{\mathrm{BA}}-\mathrm{S}_{\mathrm{MB}}\right) /\left[\left(\mathrm{S}_{\mathrm{BA}}-\mathrm{S}_{\mathrm{MB}}\right)+\mathrm{S}_{\mathrm{MB}}+\mathrm{S}_{\mathrm{MeOH}}+\mathrm{S}_{\mathrm{BME}}\right]$, or more simply

$\mathrm{Sa}_{1}=\left(\mathrm{S}_{\mathrm{BA}}-\mathrm{S}_{\mathrm{MB}}\right) /\left(100-\mathrm{S}_{\mathrm{MB}}\right)$, then $\mathrm{Sa}_{2}=\mathrm{S}_{\mathrm{MB}} /\left(100-\mathrm{S}_{\mathrm{MB}}\right)$ and $\mathrm{Sa}_{3}=\mathrm{S}_{\mathrm{BME}} /\left(100-\mathrm{S}_{\mathrm{MB}}\right)$

\subsection{Leaching Tests of Vanadium-Containing MCM-41 Catalysts}

For each test, $0.2 \mathrm{~g}$ of catalyst was introduced into a flask, then $40 \mathrm{~mL}$ of methanol was added. The mixture was stirred at room temperature for $1 \mathrm{~h}$. After filtration and washing with $40 \mathrm{~mL}$ of methanol, the solid was dried at $80^{\circ} \mathrm{C}$ overnight. Then, the samples were sent for elemental analysis.

\subsection{Recycling Test of the Catalyst}

1st Run: 48 mg of (2.5-2.5)VAl-MS-L-cal was introduced into a $50 \mathrm{~mL}$ glass flask, then $4 \mathrm{~mL}$ of substrate solution $(25 \mathrm{mmol} / \mathrm{L}$ mesitylene as internal standard and $50 \mathrm{mmol} / \mathrm{L}$ substrate in acetonitrile) was added. The flask was sealed and heated in an oil bath at $100{ }^{\circ} \mathrm{C}$ for $18 \mathrm{~h}$. After cooling to room temperature, the mixture was filtered and washed with acetonitrile. The solution was analyzed by gas chromatography, while the solid was collected, dried at $120^{\circ} \mathrm{C}$ for $6 \mathrm{~h}$, and named as (2.5-2.5)VAl-MS-L-1st.

2nd Run: $30 \mathrm{mg}$ of (2.5-2.5)VAl-MS-L-1st powder was introduced into a $50 \mathrm{~mL}$ glass flask, then $2.5 \mathrm{~mL}$ of the previous substrate solution was added. The reaction was carried out as for the 1st run. The solid after the reaction was collected, dried at $120^{\circ} \mathrm{C}$ for $6 \mathrm{~h}$, and named as (2.5-2.5)VAl-MS-L-2nd.

3rd Run: $18 \mathrm{mg}$ of (2.5-2.5)VAl-MS-L-2nd powder was introduced into a $50 \mathrm{~mL}$ glass flask, then $1.5 \mathrm{~mL}$ of the substrate solution was added. The reaction was carried out as for the 2 nd run. The solid after the reaction was collected, dried at $120{ }^{\circ} \mathrm{C}$ for $6 \mathrm{~h}$, and named as (2.5-2.5)VA1-MS-L-3rd.

4th Run: 6 mg of (2.5-2.5)VAl-MS-L-2nd powder was introduced into a $50 \mathrm{~mL}$ glass flask, then $0.5 \mathrm{~mL}$ of the substrate solution was added. The reaction was carried out as for the $3 \mathrm{rd}$ run. The solid after the reaction was collected, dried at $120{ }^{\circ} \mathrm{C}$ for $6 \mathrm{~h}$, and named as (2.5-2.5) Val-MS-L-4th.

Supplementary Materials: The following are available online at https:/ /www.mdpi.com/article/10 $.3390 /$ catal11080901/s1, Details of catalyst characterization by PXRD, TEM, $\mathrm{N}_{2}$ sorption, ${ }^{29} \mathrm{Si}$ and

${ }^{27} \mathrm{Al}$ NMR, EPR, FT-IR and UV vis-spectroscopy (with Tauc plots), and results of catalyst testing.

Author Contributions: X.L.: investigation, characterization, writing-original draft; R.C.: formal analysis; Y.L.: supervision; B.A.: editing, validation, data curation; R.T.B.: review-editing, validation, funding acquisition, resources; L.B.: conceptualization, supervision, writing-editing, funding acquisition, validation, resources. All authors have read and agreed to the published version of the manuscript. 
Funding: This work was supported by the JoRISS program between the Ecole Normale Supérieure de Lyon (France) and the East China Normal University (Shanghai, China). Xinnan Lu acknowledges the Chinese Scholarship Council and Rhône-Alpes for financial support. RTB thanks the Canada Research Chairs program and the University of Ottawa for operating support.

Data Availability Statement: All references are available in most of the scientific library or online Databases like WEB of Science; Most of them are accessible from public internet browser.

Acknowledgments: R.T.B. thanks the University of Ottawa, Canada Foundation for Innovation and Ontario Ministry of Economic Development and Innovation for essential infrastructure. L.B. and R.T.B. thank the CNRS-Université de Lyon-University of Ottawa LIA "FUNCAT" for personnel transfer support.

Conflicts of Interest: The authors declare no conflict of interest.

\section{References}

1. Huber, G.W.; Iborra, S.; Corma, A. Synthesis of transportation fuels from biomass: Chemistry, catalysts, and engineering. Chem. Rev. 2006, 106, 4044-4098. [CrossRef]

2. Besson, M.; Gallezot, P.; Pinel, C. Conversion of biomass into chemicals over metal catalysts. Chem. Rev. 2014, 114, 1827-1870. [CrossRef] [PubMed]

3. Sudasanam, P.; Peeters, E.; Makshina, E.V.; Parvulescu, V.I.; Sels, B.F. Advances in porous and nanoscale catalysts for viable biomass conversion. Chem. Soc. Rev. 2019, 48, 2366-2421. [CrossRef]

4. Alonso, D.M.; Wettstein, S.G.; Dumesic, J.A. Bimetallic catalysts for upgrading of biomass to fuels and chemicals. Chem. Soc. Rev. 2012, 41, 8075-8098. [CrossRef] [PubMed]

5. Liu, X.; Bouxin, F.P.; Fan, J.; Budarin, V.L.; Hu, C.; Clark, J.H. Recent advances in the catalytic depolymerization of lignin towards phenolic chemicals: A review. ChemSusChem 2020, 13, 4296-4317. [CrossRef] [PubMed]

6. Brosse, N.; Ibrahim, M.N.M.; Rahim, A.A. Biomass to bioethanol: Initiatives of the future for lignin. ISRN Mater. Sci. 2011, 2011, 461482. [CrossRef]

7. Jing, Y.; Dong, L.; Guo, Y.; Liu, X.; Wang, Y. Chemicals from Lignin: A review of catalytic conversion involving hydrogen. ChemSusChem 2020, 13, 4181-4198. [CrossRef]

8. Zakzeski, J.; Bruijnincx, P.C.; Jongerius, A.L.; Weckhuysen, B.M. The catalytic valorization of lignin for the production of renewable chemicals. Chem. Rev. 2010, 110, 3552-3599. [CrossRef]

9. Jiang, Y.-Y.; Yan, L.; Yu, H.-Z.; Zhang, Q.; Fu, Y. Mechanism of vanadium-catalyzed selective C-O and C-C cleavage of lignin model compound. ACS Catal. 2016, 6, 4399-4410. [CrossRef]

10. Hanson, S.K.; Wu, R.; Silks, L.A. C-C or C-O Bond Cleavage in a Phenolic Lignin Model Compound: Selectivity Depends on Vanadium Catalyst. Angew. Chem. Int. Ed. 2012, 124, 3466-3469. [CrossRef]

11. Hanson, S.K.; Baker, R.T.; Gordon, J.C.; Scott, B.L.; Thorn, D.L. Aerobic oxidation of lignin models using a base metal vanadium catalyst. Inorg. Chem. 2010, 49, 5611-5618. [CrossRef]

12. Sedai, B.; Díaz-Urrutia, C.; Baker, R.T.; Wu, R.; Silks, L.A.; Hanson, S.K. Aerobic oxidation of $\beta-1$ lignin model compounds with copper and oxovanadium catalysts. ACS Catal. 2013, 3, 3111-3122. [CrossRef]

13. Díaz-Urrutia, C.; Hurisso, B.B.; Gauthier, P.M.; Sedai, B.; Singer, R.D.; Baker, R.T. Catalytic aerobic oxidation of lignin-derived bio-oils using oxovanadium and copper complex catalysts and ionic liquids. J. Mol. Catal. A Chem. 2016, 423, 414-422. [CrossRef]

14. Díaz-Urrutia, C.; Chen, W.-C.; Crites, C.-O.; Daccache, J.; Korobkov, I.; Baker, R.T. Towards lignin valorisation: Comparing homogeneous catalysts for the aerobic oxidation and depolymerisation of organosolv lignin. RSC Adv. 2015, 5, 70502-70511. [CrossRef]

15. Sedai, B.; Baker, R.T. Copper catalysts for selective C-C bond cleavage of $\beta-\mathrm{O}-4$ lignin model compounds. Adv. Synth. Catal. 2014, 356, 3563-3574. [CrossRef]

16. Mottweiler, J.; Puche, M.; Räuber, C.; Schmidt, T.; Concepción, P.; Corma, A.; Bolm, C. Copper-and vanadium-catalyzed oxidative cleavage of lignin using dioxygen. ChemSusChem 2015, 8, 2106-2113. [CrossRef] [PubMed]

17. Muylaert, I.; Van Der Voort, P. Supported vanadium oxide in heterogeneous catalysis: Elucidating the structure-activity relationship with spectroscopy. Phys. Chem. Chem. Phys. 2009, 11, 2826-2832. [CrossRef]

18. Gao, X.T.; Bare, S.R.; Fierro, J.L.G.; Wachs, I.E. Structural characteristics and reactivity/reducibility properties of dispersed and bilayered $\mathrm{V}_{2} \mathrm{O}_{5} / \mathrm{TiO}_{2} / \mathrm{SiO}_{2}$ catalysts. J. Phys. Chem. B 1999, 103, 618-629. [CrossRef]

19. Fang, L. Surface Engineering of Mesoporous Silica for Ti-Based Epoxidation Catalysts. Ph.D. Thesis, Ecole Normale Supérieure de Lyon-ENS Lyon, Lyon, France, 2012.

20. Zheng, Y. Synthesis and Characterization of Vanadium-Containing Mesoporous Silica and Its Application in the Catalysis of Oxidation Reaction. Ph.D. Thesis, Ecole Normale Supérieure de Lyon—ENS Lyon, Lyon, France, 2014.

21. Tauc, J.; Grigorovici, R.; Vancu, A. Optical properties and electronic structure of amorphous germanium. Phys. Status Solidi 1966, 15, 627-637. [CrossRef] 
22. Swanepoel, R. Determination of the thickness and optical constants of amorphous silicon. J. Phys. E Sci. Inst. 1983, 16, 1214. [CrossRef]

23. Weber, R.S. Effect of local-structure on the UV-visible absorption edges of molybdenum oxide clusters and supported molybdenum oxides. J. Catal. 1995, 151, 470-474. [CrossRef]

24. Wu, C.-G.; Bein, T. Microwave synthesis of molecular sieve MCM-41. Chem. Commun. 1996, 925-926. [CrossRef]

25. Tompsett, G.A.; Conner, W.C.; Yngvesson, K.S. Microwave synthesis of nanoporous materials. ChemPhysChem 2006, 7, 296-319. [CrossRef] [PubMed]

26. Chaignon, J.; Bouizi, Y.; Davin, L.; Calin, N.; Albela, B.; Bonneviot, L. Minute-made and low carbon fingerprint microwave synthesis of high quality templated mesoporous silica. Green Chem. 2015, 17, 3130-3140. [CrossRef]

27. Beck, J.S.; Vartuli, J.C.; Roth, W.J.; Leonowicz, M.E.; Kresge, C.T.; Schmitt, K.D.; Chu, C.T.W.; Olson, D.H.; Sheppard, E.W.; McCullen, S.B.; et al. A new family of mesoporous molecular-sieves prepared with liquid-crystal templates. J. Am. Chem. Soc. 1992, 114, 10834-10843. [CrossRef]

28. Kresge, C.T.; Vartuli, J.C.; Roth, W.J.; Leonowicz, M.E. The discovery of ExxonMobil's M41S family of mesoporous molecular sieves. In Studies in Surface Science and Catalysis; Osamu, T., Ed.; Elsevier: Amsterdam, The Netherlands, 2004; Volume 148, pp. 53-72.

29. Busca, G.; Giamello, E. Electron spin resonance of V (4+) centers in V-Ti complex oxide powders. Mater. Chem. Phys. 1990, 25, 475-485. [CrossRef]

30. Busca, G.; Centi, G.; Marchetti, L.; Trifiro, F. Chemical and spectroscopic study of the nature of a vanadium oxide monolayer supported on a high-surface-area $\mathrm{TiO}_{2}$ anatase. Langmuir 1986, 2, 568-577. [CrossRef]

31. Dutoit, D.; Schneider, M.; Fabrizioli, P.; Baiker, A. Vanadia-Silica low-temperature aerogels: Influence of aging and vanadia loading on structural and chemical properties. Chem. Mater. 1996, 8, 734-743. [CrossRef]

32. Chao, K.; Wu, C.; Chang, H.; Lee, L.; Hu, S.-F. Incorporation of vanadium in mesoporous MCM-41 and microporous AFI zeolites. J. Phys. Chem. B 1997, 101, 6341-6349. [CrossRef]

33. Gao, X.T.; Wachs, I.E. Investigation of surface structures of supported vanadium oxide catalysts by UV-vis-NIR diffuse reflectance spectroscopy. J. Phys. Chem. B 2000, 104, 1261-1268. [CrossRef]

34. Lee, E.L.; Wachs, I.E. Molecular design and in situ spectroscopic investigation of multilayered supported $\mathrm{M}_{1} \mathrm{O}_{\mathrm{x}} / \mathrm{M}_{2} \mathrm{O}_{\mathrm{x}} / \mathrm{SiO}_{2}$ catalysts. J. Phys. Chem. C 2008, 112, 20418-20428. [CrossRef]

35. Lee, E.L.; Wachs, I.E. Surface chemistry and reactivity of well-defined multilayered supported $\mathrm{M}_{1} \mathrm{O}_{\mathrm{x}} / \mathrm{M}_{2} \mathrm{O}_{\mathrm{x}} / \mathrm{SiO}_{2}$ catalysts. J. Catal. 2008, 258, 103-110. [CrossRef]

36. Moussa, N.; Ghorbel, A. UV-vis-DR study of $\mathrm{VO}_{x} / \mathrm{SiO}_{2}$ catalysts prepared by sol-gel method. Appl. Surf. Sci. 2008, 255, 2270-2275. [CrossRef]

37. Gao, X.; Bare, S.R.; Weckhuysen, B.M.; Wachs, I.E. In situ spectroscopic investigation of molecular structures of highly dispersed vanadium oxide on silica under various conditions. J. Phys. Chem. B 1998, 102, 10842-10852. [CrossRef]

38. Bulanek, R.; Capek, L.; Setnicka, M.; Cicmanec, P. DR UV-vis Study of the Supported Vanadium Oxide Catalysts. J. Phys. Chem. C 2011, 115, 12430-12438. [CrossRef]

39. Bulanek, R.; Cicmanec, P.; Sheng-Yang, H.; Knotek, P.; Capek, L.; Setnicka, M. Effect of preparation method on nature and distribution of vanadium species in vanadium-based hexagonal mesoporous silica catalysts: Impact on catalytic behavior in propane ODH. Appl. Catal. A-General 2012, 415, 29-39. [CrossRef]

40. He, J.; Yang, X.; Men, B.; Wang, D. Interfacial Mechanisms of Heterogeneous Fenton Reactions Catalyzed by Iron-Based Materials: A Review. J. Environ. Sci. 2016, 39, 97-109. [CrossRef]

41. Wigington, B.N.; Drummond, M.L.; Cundari, T.R.; Thorn, D.L.; Hanson, S.K.; Scott, S.L. A Biomimetic Pathway for VanadiumCatalyzed Aerobic Oxidation of Alcohols: Evidence for a Base-Assisted Dehydrogenation Mechanism. Chem. Eur. J. 2012, 18, 14981-14988. [CrossRef]

42. Khenkin, A.M.; Neumann, R. Oxidative $\mathrm{C}-\mathrm{C}$ bond cleavage of primary alcohols and vicinal diols catalyzed by $\mathrm{H}_{5} \mathrm{PV}_{2} \mathrm{Mo}_{10} \mathrm{O}_{40}$ by an electron transfer and oxygen transfer reaction mechanism. J. Am. Chem. Soc. 2008, 130, 14474-14476. [CrossRef]

43. Hanson, S.K.; Baker, R.T.; Gordon, J.C.; Scott, B.L.; Sutton, A.D.; Thorn, D.L. Aerobic oxidation of pinacol by vanadium (V) dipicolinate complexes: Evidence for reduction to vanadium (III). J. Am. Chem. Soc. 2009, 131, 428-429. [CrossRef]

44. Ohler, N.; Bell, A.T. Study of the elementary processes involved in the selective oxidation of methane over $\mathrm{MoOx}_{\mathrm{SiO}}$. J. Phys. Chem. B 2006, 110, 2700-2709. [CrossRef]

45. Chempath, S.; Bell, A.T. A DFT study of the mechanism and kinetics of methane oxidation to formaldehyde occurring on silica-supported molybdena. J. Catal. 2007, 247, 119-126. [CrossRef]

46. Getsoian, A.B.; Zhai, Z.; Bell, A.T. Band-gap energy as a descriptor of catalytic activity for propene oxidation over mixed metal oxide catalysts. J. Am. Chem. Soc. 2014, 136, 13684-13697. [CrossRef]

47. Zhang, W.; Innocenti, G.; Oulego, P.; Gitis, V.; Wu, H.-H.; Ensing, B.; Cavani, F.; Rothenberg, G.; Shiju, N.R. Highly selective oxidation of ethyl lactate to ethyl pyruvate catalysed by mesoporous vanadia-titania. ACS Catal. 2018, 8, 2365-2374. [CrossRef]

48. Yun, D.; Wang, Y.; Herrera, J.E. Ethanol partial oxidation over $\mathrm{VO}_{\mathrm{x}} / \mathrm{TiO}_{2}$ catalysts: The role of titania surface oxygen on vanadia reoxidation in the Mars-van Krevelen mechanism. ACS Catal. 2018, 8, 4681-4693. [CrossRef] 